\title{
Advanced mapping of the human white matter microstructure better separates elite sports participation
}

\author{
Bradley Caron, Daniel Bullock, Lindsey Kitchell, Brent McPherson, Derek Kellar, Hu Cheng, Sharlene \\ Newman, Nicholas Port, and Franco Pestilli
}

\begin{abstract}
Collision-sport athletes, especially football players, are exposed to a higher number of repetitive head impacts. Little is known, however, regarding the effects of long-term exposure to repetitive head impacts on brain tissue structure and the locations (i.e. superficial or deep tissue structures) affected. On top of this, little is known about the effects of highly competitive, strenuous, long-term athletics on brain tissue structure. We investigated this relationship using advanced microstructural mapping techniques. Specifically, we examined the baseline differences in collegiate athletic participants by using two models of the diffusion-weighted magnetic resonance imaging signal (the Diffusion Tensor and NODDI model). DTI and NODDI parameters were mapped in both cortical and subcortical structures, as well as in the major white matter tracts. Three groups of young adults participated in our study; IU football players, cross country runners, and non-athlete students. For both models, athletes were found to have consistently higher measures of microstructure than controls. The NODDI model parameters showed stronger results indicating that it might be more sensitive to capturing differences in brain white matter tissue microstructure than the DTI model. This was the first investigation into the effects of repetitive head impacts to use an open-source data processing platform brainlife.io. Data and analyses for this study are available at https://doi.org/10.25663/brainlife.pub.14.
\end{abstract}

Acknowledgments. This research was supported by NSF OAC-1916518, NSF IIS-1912270, NSF, IIS-1636893, NSF BCS-1734853, NIH NIDCD 5R21DC013974-02, NIH 1R01EB029272-01, NIH NIMH 5T32MH103213, the Indiana Spinal Cord and Brain Injury Research Fund, Microsoft Faculty Fellowship, the Indiana University Areas of Emergent Research Initiative "Learning: Brains, Machines, Children." We thank Soichi Hayashi, and David Hunt for contributing to the development of brainlife.io, Craig Stewart, Robert Henschel, David Hancock and Jeremy Fischer for support with jetstream-cloud.org (NSF $\mathrm{ACl}-1445604)$. We also thank The Indiana University Lawrence D. Rink Center for Sports Medicine and Technology and Center for Elite Athlete Development for contributing funding to athletic scientific research and for the development of a new research facility.

\section{Introduction}

Elite athletes are highly motivated individuals with physical and psychological characteristics that make them uniquely fit to compete in a sport (Figure 1a). In order to get to the elite level of competition within a given sport, athletes must often go through intensive and extensive physical conditioning and exercise, including cardiovascular endurance training and weight lifting. This conditioning is in addition to the physically-demanding aspects of their respective sports. This training has been shown to have a great deal of both beneficial and potentially harmful effects on all 79 organ systems of the body. As of today, a great deal of research is invested in identifying the potentially harmful effects of elite athletics, especially contact and collision-sports athletes, on the brain tissue of athletes. However, little is known regarding the inherent differences in brain tissue structure between elite sports athletes compared to the normal population (Figure 1b). In this paper, we investigated the baseline differences in white matter microstructure in two groups of collegiate athletes (football players, cross country runners) and group matched controls (Figure 1a).

The potential risks to the brain tissue from participation in impact-prone sports are of major interest to society (Montenigro et al., 2017). In Division 1 NCAA Collegiate football, a starting player may receive up to 1,400 head impacts in a single season, and the average starting player receivers 200-400 impacts per season, with peak linear and rotational acceleration of around $20 \mathrm{~g}$ and $1400 \mathrm{rad} / \mathrm{s}^{2}$, respectively (Broglio et al., 2010; Crisco et al., 2011, 2010; Gysland et al., 2012; Myer et al., 2016b). For perspective, automobile accidents have been shown to have peak linear and rotational accelerations ranging from $29 \mathrm{~g}$ to $120 \mathrm{~g}$ and $2100-9400 \mathrm{rad} / \mathrm{s}^{2}$, respectively (Zhang et al., 2006). Among elite athletes, American football players have received increasing attention due to the high rate of the body and head collisions in the sport and the higher prevalence of symptoms related to neurodegenerative disorders in retired athletes as compared to the general population (Gavett et al., 2011; McKee et al., 2009; Mez et al., 2017; Saulle and Greenwald, 2012). The potential for brain tissue damage is greater in these athletes than 
those that participate for example, in non-collision sports, such as cross country. Historically, the concern regarding the effects of head impacts in collision sport athletes has been focused on concussion and traumatic brain injury (TBI). However, only a small proportion of head impacts in American football result in a concussion diagnosis, as the estimated rate of concussions is less than 1.5 concussions across both practice and game sessions (Kerr et al., 2017). The concern among some scientists is that repetitive head impacts may be more detrimental to athletes than concussions, as they have been associated with a higher risk of developing neurodegenerative disorders, most-notably Chronic Traumatic Encephalopathy (Critchley, 1957; Gavett et al., 2011; McKee et al., 2009; Roberts, 1969).

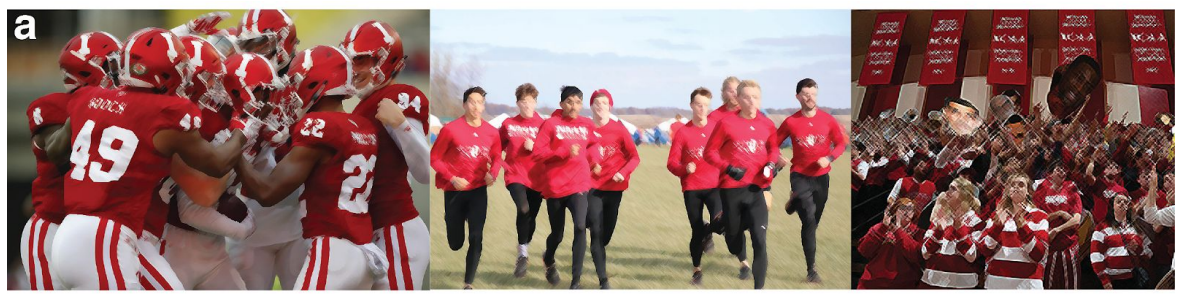

b

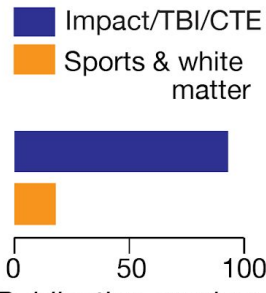

Publication number
C
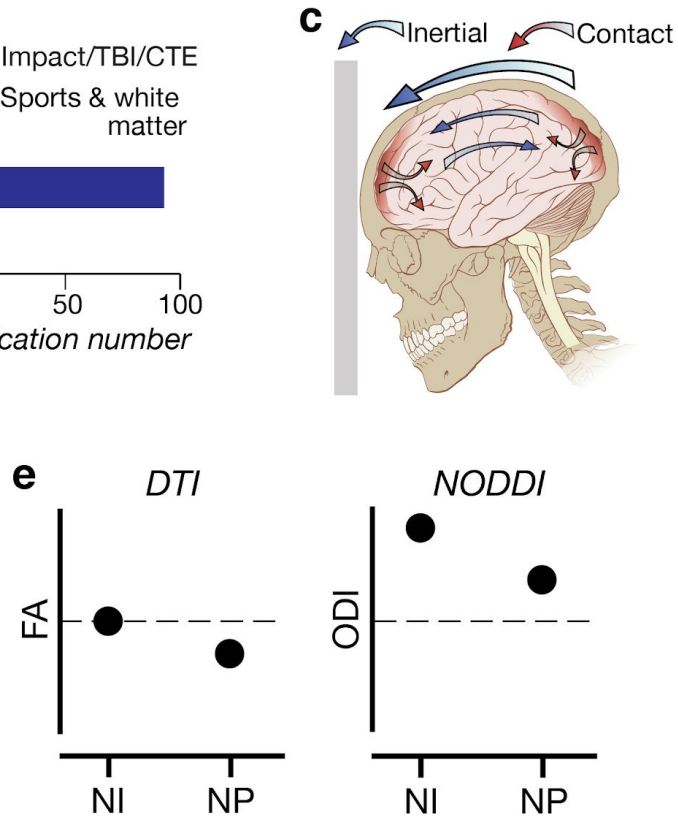

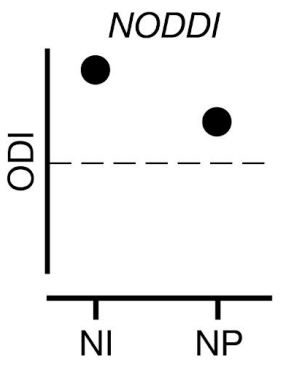

d Healthy \& Oriented
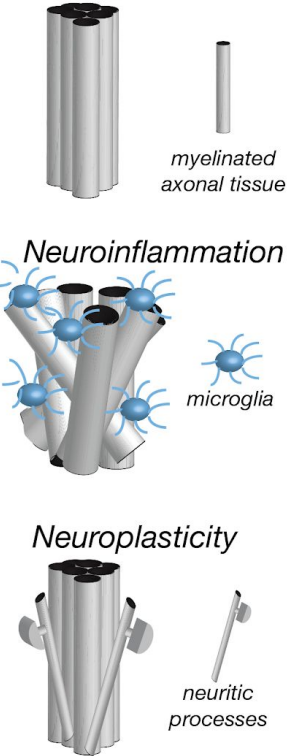

Figure 1. Multiple effects of head impact and sports participation on deep and superficial brain tissue. a. Example of collision (left) and non-collision (middle) sports and non-athlete (right) participants investigated in this study. Athletics participation has been found to have a variety of psychological and physiological effects on the body, including the brain. However, little is known regarding the exact effects of elite sports participation on brain tissue structure. Note. Final images will be added to panel a, after acceptance to the journal. b. The effects of elite sports participation on white matter tissue structure is much less investigated than the detrimental effects of impact-prone sports, as indicated by the number of PubMed citations obtained. Searches conducted December 2019, see Methods for more details. c. Illustration of the potential effects of collisions on brain tissue. Inertial forces (blue arrows) generated from the linear or rotational accelerations of the impact and contact affect primarily deep and long-rage neuronal fibers and white matter. Dispersive forces (red arrows) generated by a single point head impact. Inertial forces (blue) travel along the major axis of head motion during head rotation - we suggest that these forces are most likely to affect long-range neuronal fibers and deep white matter tissue. Contact forces (red) are local and disperse in multiple, fanning, directions - we speculate that these forces are more likely to affect superficial brain structures and superficial white matter. d. The effects of sports participation and repetitive head impacts can have differential impacts on neuronal tissue. Healthy neuronal fibers (i.e. top) can be highly oriented, and densely packed. Neuronal fibers (i.e. middle) undergoing repetitive sub-concussive hits may become damaged, less cohesively oriented, less packed, or even swollen due to neuroinflammatory processes. (Image modified from Wikipedia, $\underline{\mathrm{CC}}$ BY license, original by P.J. Lynch). However, the same changes in orientation of neurites can be observed via neuroplasticity and generation of new neuritic processes from sports participation (bottom). e. Example demonstrating the inability of the fractional anisotropy (FA) measure from the Diffusion Tensor Model (DTI) to identify differences in the neuroinflammatory condition, especially with microglial infiltration, and will show minor differences in neuroplastic situations shown in d, but orientation dispersion index (ODI) from the Neurite Orientation Dispersion Density Imaging (NODDI) model is able to 
distinguish between the two and will be able to identify neuroinflammatory processes such as microglial infiltration (Yi et al., 2019).

Different types of forces affect the brain following an impact to the head or body. These forces are generally subdivided into contact and inertial (McAllister, 2011; Meaney and Smith, 2011) (Figure 1c). Immediately following an impact, the acceleration due to the contact forces is loaded onto the surface of the brain, potentially imposing superficial brain tissue compression and dispersion (Figure 1c red). Inertial forces follow thereafter translating the impact onto the deep brain tissue, affecting also long-range brain structures (Figure 1c blue). Contact and inertial forces have been shown to lead to a plethora of alterations to brain tissue structure such as neuronal membrane permeability and axonal swelling (Geddes et al., 2003a, 2003b; LaPlaca et al., 2005), neuronal response alterations(Kao et al., 2004; Lamb et al., 1997; Zhang et al., 1996), axonal beading (Gaetz, 2004; Kilinc et al., 2009, 2008; Maxwell and Graham, 1997), shearing of the long-range neuronal fibers (Adams et al., 1989, 1982; Gennarelli et al., 1982; Johnson et al., 2013; Nevin, 1967; Povlishock et al., 1983; Povlishock and Becker, 1985; Povlishock and Katz, 2005), inflammatory cascades (Giza and Hovda, 2014; Israelsson et al., 2008; Shultz et al., 2012) all the way to Wallerian degeneration and axotomy (Armstrong et al., 2016; Frati et al., 2017; Maxwell et al., 2015; Pierpaoli et al., 2001; Rotshenker, 2007; Yoshimine et al., 2018). Athletes are exposed to increased risks of musculoskeletal injury, increased stress and anxiety, with increased risk for chronic inflammation(Gleeson, 2007; Hootman et al., 2007; Rice et al., 2019). These alterations and biological cascades from repetitive head impacts are in addition to increased risks of musculoskeletal injury, increased stress, and anxiety, with increased chronic inflammation (Gleeson, 2007; Hootman et al., 2007; Rice et al., 2019) and increased exposure to reactive oxygen species from elite sports participation (Hadžović-Džuvo et al., 2014; Powers et al., 2020) and the athletic conditioning required. This increased inflammation may potentially impact brain tissue microstructure and lead to neuroinflammatory processes (Huang et al., 2018; Kempuraj et al., 2017) including microglial infiltration and mitochondrial dysfunction (Figure 1d). Thus, in order to fully understand the full effects of repetitive head impacts and the potential determinants seen in some former impact-prone athletes, it is important to fully clarify the baseline differences (i.e. non-contact related) between elite sports athletes and the general population.

The positive benefits of physical exercise and activity generally are well-documented. Beneficial effects of physical activity range from improved cognition (Hillman et al., 2008; Voss et al., 2011), overall better wellbeing (Penedo and Dahn, 2005), longer lifespan (Reimers et al., 2012), and even increased integrity of brain tissue structure (Bracht et al., 2016; Chaddock-Heyman et al., 2018, 2014; Esteban-Cornejo et al., 2019; Hayes et al., 2015; Ruotsalainen et al., 2020; Saraulli et al., 2017; Voss et al., 2013) (Figure 1d). Physical exercise has even been documented to lead to increased synaptogenesis and dendritic spine density (El-Sayes et al., 2019; Hötting and Röder, 2013). Long-term physical exercise has also been shown to moderate the effects of the brain to reactive oxidative species (Brunetta et al., 2020; Radak et al., 2013) and inflammatory processes in healthy and elderly populations(Seo et al., 2019). Despite this evidence of benefits of physical activity and exercise, the full effect of elite sports participation on brain tissue structure is not well understood. Specifically, the potential effect of sport participation on the brain white matter has not been fully characterized. For example, some investigations into white matter tissue structure of elite athletes find increases in measures of structural integrity (Hänggi et al., 2015), while others show decreases in those measures (Deng et al., 2018; Hänggi et al., 2010; Jäncke et al., 2009). This lack of consensus in the literature highlights the need for a more thorough characterization of the effects of elite sports participation on the brain tissue structure of athletes. This is especially important for understanding the potentially harmful effects of a specific class of sports, impact-prone sports.

Diffusion-weighted magnetic resonance imaging (dMRI) and tractography allow measuring white matter tissue in the living human brain. The method provides a unique opportunity to clarify the positive and negative effects of sports participation. The method allows measuring the macro- and microstructural composition of the brain white matter tissue in vivo (Basser et al., 1994a; Basser and Jones, 2002). Recent advancements in diffusion MRI acquisition parameters, including the use of multi-shell acquisitions to exploit multi-parameter models to derive brain microstructural tissue properties such as neurite orientation dispersion and density (Zhang et al., 2012), show increased promise for improving discrimination of brain tissue changes in a variety of human disease relative to more traditional single-shell acquisition parameters and models (Pestilli, 2018; Rokem et al., 2017; Thomason and Thompson, 2011; Wandell, 2016). Such models can also be used to provide neurite composition information for both deep (Jelescu and Budde, 2017; Sato et al., 2017; Schilling et al., 2018) and cortical white matter (Fukutomi et al., 2018) structures, for instance. 
Advanced diffusion methods, including multi-shell acquisition and higher order diffusion signal models, have been previously used to examine brain tissue structure across multiple large tissue structures. For example, these methods has been previously used to examine brain tissue structural differences in deep white matter structures (Rokem et al., 2017) (hereafter referred to as major white matter tracts), superficial white matter (Fukutomi et al., 2018) (i.e., white matter mixed with neuronal cell bodies, such as white matter in the cortex; hereafter referred to as cortical white matter) and subcortical (i.e. amygdala, hippocampus, basal ganglia) white matter. These methods have been used to measure the putative effects of concussion, concussion history, and repetitive head impacts, including disorientation of myelinated structures, disruption of myelin properties, axonal swelling and tau-accumulation (Churchill et al., 2018, 2017a; Mayer et al., 2017). A great deal of previous work has studied structural differences in in a single tissue-type or combination of tissue types, including major (Bahrami et al., 2016; Bazarian et al., 2014; Churchill et al., 2017a, 2017b; Davenport et al., 2016a, 2016b; Koerte et al., 2012; Kuzminski et al., 2018; Lefebvre et al., 2020; Mayinger et al., 2018; McAllister et al., 2014; Merchant-Borna et al., 2016; Saghafi et al., 2018; Sollmann et al., 2018; Stamm et al., 2015; Strauss et al., 2020; Yuan et al., 2018), cortical and subcortical (Gong et al., 2018; Mayer et al., 2017; Meier et al., 2016) white matter between collision sport participants and controls (i.e., non-athletes, non-collision sports athletes, within-subject longitudinal). However, few studies (Lefebvre et al., 2020; Mayer et al., 2017) have looked at all three tissue-types to fully characterize the effects of sports participation across the entirety of the human brain.

To fully characterize the structural properties of the groups of subjects in our study, we compared the microstructural properties of major white matter tracts, cortical, and subcortical white matter using two of the dominant models (Figure 1e). We compared results using the original Diffusion Tensor model (DTI; (Basser et al., 1994b; Pierpaoli et al., 1996)) and the relatively more recent, Neurite Orientation Dispersion Density Imaging (NODDI; (Zhang et al., 2012)) model. More specifically, we compared the performance of DTI and NODDI in identifying differences between the groups. We used a state-of-the-art, anatomically informed approach to measuring white matter tracts (Mori et al., 2005; Pestilli et al., 2014; Yeatman et al., 2012), cortical white matter (Destrieux et al., 2010; Fukutomi et al., 2018), and subcortical white matter structures (Bruce Fischl et al., 2002). Microstructural measurements demonstrated widespread differences in tissue microstructure across a majority of major structures (cortical and deep white matter structures) between athletes and non-athletes, with collision-sports athletes demonstrating the greatest differences from non-athletes. We performed additional tests to rule out effects due to a series of alternative nuisance drivers such as brain tissue size and volume.

\section{Methods}

Open cloud computing services and brainlife.io. We investigated how the microstructural tissue properties in major white matter tracts differed among the three groups: football players, cross country runners, and non-athlete collegiate students. To do so, we developed a reproducible data processing workflow using the cloud computing platform brainlife.io (Avesani et al., 2019). Our workflow consisted of 17 brainlife.io Apps (see also Table 1). Specifically, sixty one major white-matter tracts (Mori et al., 2005; Pestilli, 2018; Rokem et al., 2017; Yeatman et al., 2012) were identified using the Anatomically-constrained tractography (ACT; brainlife.app.297) app to perform tractography (Smith et al., 2012; Takemura et al., 2016) and the White Matter Anatomy Segmentation (brainlife.app.188) app for the segmentation (Bullock et al., 2019) of these 61 major white matter tracts (Figure 3a; see also Methods: White matter microstructure modelling (Tractography) and White matter microstructure modelling (Segmentation)). We used the NODDI (brainlife.app.365) and DTI (brainlife.app.292) apps to estimate the microstructural properties of the previously segmented major white matter tissue using parameters derived with the NODDI model (Daducci et al., 2015; Zhang et al., 2012) and the DTI model (Basser et al., 1994a, 1994b). These maps were combined with the Tract Analysis Profiles (brainlife.app.361) app to map the microstructural parameters on to the anatomy of each tract of interest (Yeatman et al., 2012). See also Methods: White matter microstructure modelling: Tract profile generation. We used an empirically-documented categorization scheme that grouped major white matter tracts that have been historically associated with a variety of functional domains and behaviors (Schmahmann and Pandya, 2006) (Figure 3a). The NODDI model estimates brain microstructural properties such as neurite orientation dispersion (i.e., ODI), neurite density (i.e., NDI), and CSF volume fraction (i.e., ISOVF). See Methods: White matter microstructure modelling: Neurite Orientation Dispersion and Density Imaging (NODDI) for details on the microstructural modelling and interpretation. The DTI model estimates brain microstructural properties such as fractional anisotropy (FA), mean diffusivity (MD), axial diffusivity (AD), and radial diffusivity (RD). See Methods: White matter microstructure modelling (DTI) for details on the microstructural modelling. 
We also investigated how the microstructural properties of the cortical and subcortical white matter might differ among football players, cross country runners, and non-athletes. We used the Freesurfer app (brainlife.app.0) to segment cortical and subcortical white matter parcels (Fischl, 2012) (Figure 5a; see also Methods: Anatomical data (T1w) processing). We used an empirically-documented parcellation scheme that grouped cortical white matter parcels into eight regions that have been historically associated with a variety of functional domains and behaviors (Chayer and Freedman, 2001; Ebbesen and Brecht, 2017; Gerard et al., 1933; Gogolla, 2017; Irimia et al., 2012; Kanwisher, 2010; Rajmohan and Mohandas, 2007; Scott et al., 2000; Singh-Curry and Husain, 2009; Tootell et al., 1998) (Figure 5a). We used the NODDI (brainlife.app.365), DTI (brainlife.app.292), and Cortex Tissue Mapping (brainlife.app.379) apps to map microstructural tissue properties derived using the NODDI model and DTI model in the cortical white matter parcels (Fukutomi et al., 2018). Using Freesurfer, we also segmented subcortical structures and mapped the average microstructural tissue properties derived using NODDI and DTI in the subcortical white matter. See Methods: Anatomical data (T1w) processing) and Cortical and subcortical white matter mapping for more details on the mapping and segmentation

Availability of data and open services for the reproducibility of the data analyses. Deidentified data are shared minimally processed and are published using brainlife.io. The brainlife.io platform allows publishing processed data and associated analyses step (Apps) integrated into a single record referenced by a digital-object-identifier (DOI; (Avesani et al., 2019). Apps and data produced as part of the present project are published on brainlife.io interlinked and each dataset is preserved with associated provenance information to allow other investigators to download the analyses or reuse the App on the cloud platform. Data and Apps associated with the present project are published and preserved at https://doi.org/10.25663/brainlife.pub.14.

The data processing pipeline (Table 1) outlined in the Methods section of this paper can be accessed as computable applications via open services hosted at brainlife.io (Avesani et al., 2019; Stewart et al., 2015; Towns et al., 2014), or as static code available on https://github.com/brainlife. The services allow the processing of data in the same fashion outlined below. The services can be viewed here https://doi.org/10.25663/brainlife.pub.14 and links to public GitHub repositories with their source code are included for each step described below and in Table 1. Code (MATLAB, python) for the analyses performed in this paper is freely available at https://github.com/bacaron/athlete-brain-study.

\begin{tabular}{|c|c|c|c|}
\hline Application & Github repository & Open Service DOI & GitHub Branch \\
\hline FSL Anat & https://github.com/brainlife/app-fsl-anat & $10.25663 /$ brainlife.app.273 & $\mathrm{v} 1.0$ \\
\hline $\begin{array}{l}\text { Freesurfer Cortical } \\
\text { and Subcortical } \\
\text { Segmentation }\end{array}$ & https://github.com/brain-life/app-freesurfer & 10.25663/bl.app.0 & 1.11 \\
\hline $\begin{array}{c}\text { Tissue-Type } \\
\text { Segmentation }\end{array}$ & https://github.com/brainlife/app-mrtrix3-5tt & 10.25663/brainlife.app.239 & binarize-v1.0 \\
\hline $\begin{array}{c}\text { Multi-Atlas Transfer } \\
\text { Tool (MaTT) }\end{array}$ & https://github.com/faskowit/app-multiAtlasTT & 10.25663/bl.app.23 & 0.0 .5 \\
\hline $\begin{array}{l}\text { FSL Topup \& Eddy - } \\
\text { CUDA }\end{array}$ & https://github.com/brainlife/app-FSLTopupEddy & 10.25663/brainlife.app.287 & cuda-v1.0 \\
\hline Mrtrix3 preproc & https://github.com/brain-life/app-mrtrix3-preproc & $10.25663 / \mathrm{bl} . \mathrm{app} .68$ & 1.6 \\
\hline SNR Calculation & https://github.com/davhunt/app-snr in cc/tree/plot & 10.25663/bl.app.120 & plot \\
\hline FSL BET & https://github.com/brain-life/app-FSLBET & 10.25663/brainlife.app.163 & dwi \\
\hline NODDI Fit via Amico & https://github.com/brain-life/app-noddi-amico & 10.25663/brainlife.app.365 & 1.3 \\
\hline FSL DTIFIT & https://github.com/brainlife/app-fsIDTIFIT & 10.25663/brainlife.app.292 & $\mathrm{v} 1.0$ \\
\hline $\begin{array}{c}\text { Cortex Tissue } \\
\text { Mapping }\end{array}$ & https://github.com/brainlife/app-cortex-tissue-mapping & 10.25663/brainlife.app.379 & v1.1 \\
\hline $\begin{array}{c}\text { Fit Constrained } \\
\text { Spherical } \\
\text { Deconvolution } \\
\text { Model For Tracking }\end{array}$ & https://github.com/bacaron/app-mrtrix3-act & 10.25663/brainlife.app.238 & $\begin{array}{c}\text { csd_generation-v1 } \\
.0\end{array}$ \\
\hline \begin{tabular}{|c|} 
Anatomically \\
Constrained \\
Tractography using \\
precomputed $5 t \mathrm{E}$ \\
CSD \\
\end{tabular} & https://github.com/bacaron/app-mrtrix3-act & 10.25663/brainlife.app.297 & 1.3 \\
\hline merge2TCKs & https://github.com/bacaron/app-mergeTCK & 10.25663/brainlife.app.305 & two-tck \\
\hline $\begin{array}{l}\text { White Matter } \\
\text { Anatomy } \\
\text { Segmentation }\end{array}$ & https://github.com/brainlife/app-wmaSeg & 10.25663/brainlife.app.188 & 3.7 \\
\hline $\begin{array}{l}\text { Remove Tract } \\
\text { Outliers }\end{array}$ & https://github.com/brainlife/app-removeTractOutliers & 10.25663/brainlife.app.195 & 1.3 \\
\hline $\begin{array}{c}\text { Tract Analysis } \\
\text { Profiles }\end{array}$ & https://github.com/brain-life/app-tractanalysisprofiles & 10.25663/brainlife.app.361 & 1.8 \\
\hline Tractography Quality & https://github.com/brainlife/app-tractographyQualityCheck & 10.25663/brainlife.app.189 & 1.2 \\
\hline
\end{tabular}


Table 1. Description, weblinks, and DOI for the open cloud services used to process the data.

Data sources for the analyses of the scientific articles. Data utilized for Figure 1c were collected by performing customized searches on the NIH PubMed portal. Search results were generated using the format:

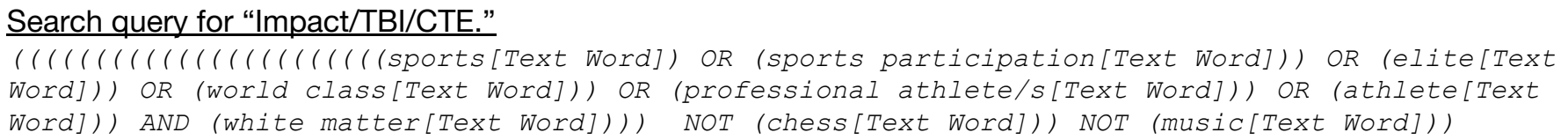

Search query for "Sports \& white matter."

NOT (Concussion [Text Word])) NOT (concussion [Text Word])) NOT (head trauma[Text Word])) NOT (brain trauma[Text Word])) NOT (brain injury[Text Word])) NOT (TBI[Text Word])) NOT (brain damage[Text Word])) NOT (concussions[Text Word])) NOT (repetitive head impacts[Text Word])) NOT (RHI[Text Word])) NOT (head impact[Text Word])) NOT (CTE[Text Word])) NOT (injury[Text Word]) .

Literature searches were conducted on December 20, 2019.

Neuroimaging data sources. Data were collected at the Indiana University Imaging Research Facility (IRF, https://www.indiana.edu/ irf/home).

Study participants. A total of fifty-one male participants participated in the study. Twenty-one participants were 4th- and 5th-year varsity Indiana University (IU) football "starters" (age $21.1 \pm 1.5$ years). This number accounts for approximately $60 \%$ of the total IU football team active players matching our criteria. Potential participants were excluded if they reported a diagnosed concussion within 6 months of the beginning of the study. One football player did not complete the study, and three football players did not complete the diffusion MRI (dMRI) scans. This left 17 usable datasets from the football group. Following scanning, football players received a socioeconomic status survey gathering information regarding estimated family income and the area in which they were raised (i.e. urban, small town, suburbs). Nineteen members of the IU cross country running team (age $20.2 \pm$ 2.5 years) were included as a non-collision sports group and were matched to the football players based on age and experience level. Three of the players' anatomical (T1w) images were unusable due to aliasing and motion artifacts and thus their data was not included. This left us with 16 eligible members. Our access to the socioeconomic status of non-athlete undergraduates was limited to Psychology and Neuroscience undergraduates who had filled out the socioeconomic survey in an IRB approved subject pool. Eleven controls (non-athletes) participants were selected from the limited pool matched to the football players (age $19.9 \pm 3$ ). Two of the participants' diffusion data contained strong distortions artifacts that were beyond correction with our processing protocol and thus their data were not included, leaving nine usable datasets. Overall, the released dataset contains usable data from 17 football players, 16 cross country runners, and 9 non-athletes for analysis $(\mathrm{N}$ $=42$ ). In regards to concussion history, two football players had been diagnosed with a concussion approximately 3 years before the study and one player had been diagnosed approximately 2 years before the study. There was no history of concussion in the cross country runners while they were at IU. No information was collected regarding the concussion history of the participants before their arrival at IU, however. Although we did not have this information available, we can estimate around $7.25 \%$ of football players to have been diagnosed with a concussion prior to college given estimates from the literature (Dompier et al., 2015). Participants gave informed written consent that was approved by the Indiana University Institutional Review Board. All participants were recruited through flyers handed out by the athletic trainers of each team or posted around campus. Participants were compensated for participation with a cash payment.

Neuroimaging parameters. Participants were imaged using a 3-Tesla TIM Trio scanner located in the Imaging Research Facility at Indiana University. A 12-channel head coil was used as the 32-channel coil did not fit the heads of our larger subjects. Diffusion-weighted magnetic resonance imaging (dMRI) data were collected with two phase-encoding schemes, i.e anterior-posterior (AP) and posterior-anterior (PA). The following parameters were used for the dMRI pulse sequence: TR/TE $=4930 / 99.6 \mathrm{~ms}$, iPAT acceleration factor $=2$; voxel size $=2 \times 2 \times 2$ $\mathrm{mm}$ isotropic, 143 diffusion-weighting directions, including sixty-four directions with $b=1000 \mathrm{~s} / \mathrm{mm} 2$ and sixty-four directions with $b=2000 \mathrm{~s} / \mathrm{mm} 2$. Fifteen non-weighted images were also acquired $(b=0)$. One T1-weighted (T1w) anatomical image was acquired for each participant using the following sequence: TR/TE = $1800 / 2.67 \mathrm{~ms}, \mathrm{Tl}=900 \mathrm{~ms}$, flip angle $=9^{\circ}$, bandwidth $=150 \mathrm{~Hz} /$ pixel, 160 sagittal slices, FOV = $256 \mathrm{~mm}$, matrix = 
256x256, slice thickness $=1 \mathrm{~mm}$, resulting in $1 \mathrm{~mm}$ isotropic voxels. The total acquisition time for T1w was 7 minutes and $42 \mathrm{~s}$.

Anatomical data (T1w) processing. Raw anatomical (T1w) images were preprocessed using the fsl_anat functionality provided by the FMRIB Software Library (FSL) (Jenkinson et al., 2012; Smith et al., 2004; Woolrich et al., 2009). In brief, the raw anatomical (T1w) images were cropped and reoriented to match the orientation of the MNI152 template. Then, the cropped and reoriented images were linearly and non-linearly aligned to the MNI152 $0.8 \mathrm{~mm}$ template using flirt and fnirt functionality respectively (Greve and Fischl, 2009; Jenkinson et al., 2002; Jenkinson and Smith, 2001). The linearly aligned images will hereafter be referred to as the 'acpc aligned' anatomical (T1w) images. The warps generated from the non-linear alignment were subsequently used for mapping diffusion metrics to the cortex (Fukutomi et al., 2018). Following alignment, the 'acpc aligned' anatomical (T1w) images were processed via Freesurfer's recon-all function to generate pial (i.e. cortical) and white matter surfaces and to parcellate the brain into known anatomical atlases (Dale et al., 1999; Dale and Sereno, 1993; Desikan et al., 2006; B. Fischl et al., 2002; Fischl et al., 2004a, 2004b, 2001, 1999a, 1999b; Fischl and Dale, 2000; Han et al., 2006; Jovicich et al., 2006; Kuperberg et al., 2003; Reuter et al., 2012, 2010; Reuter and Fischl, 2011; Rosas et al., 2002; Salat et al., 2004; Segonne et al., 2007, 2004). The Destrieux (aparc.a2009s) atlas was used for subsequent white matter tract segmentation and for mapping of diffusion metrics to the cortical surface. Finally, the 'acpc aligned' anatomical (T1w) image was segmented into different tissue-types using MrTrix3.0's 5ttgen functionality (Segonne et al., 2007; Tournier et al., 2019). The gray- and white-matter interface mask was subsequently used as a seed mask for white matter tractography (Smith et al., 2012).

Diffusion data (dMRI) processing. Raw dMRI images were first reoriented to match the orientation of the MNI152 template using the fslreorient2std command provided by FSL. Images containing opposite-facing distortions due to the phase encoding direction (i.e. PA and AP) were then combined into a single corrected image in a method similar to the one described in Andersson and colleagues (2003) (Andersson et al., 2003; Smith et al., 2004) (i.e. topup command) as provided by FSL (Jenkinson et al., 2012; Woolrich et al., 2009). Eddy-current and motion correction was then applied via the eddy_cuda8.0 with replacement of outlier slices (i.e. repol) command provided by FSL (Andersson et al., 2018, 2017, 2016; Andersson and Sotiropoulos, 2016). MRTrix3's dwigradcheck functionality was used to check and correct for potential misaligned gradient vectors following top-up and eddy (Jeurissen et al., 2014a). Following this, dMRI images were debiased using ANT's $n 4$ functionality (Tustison et al., 2014) and the background noise was cleaned using MrTrix3.0's dwidenoise functionality (Veraart et al., 2016). Finally, the preprocessed dMRI images were registered to the 'acpc aligned' anatomical (T1w) image using FSL's epi_reg functionality (Greve and Fischl, 2009; Jenkinson et al., 2002; Jenkinson and Smith, 2001) and resliced to $1 \mathrm{~mm}$ isotropic voxels. A brainmask of the preprocessed, acpc-aligned dMRI images were then used for subsequent modelling and tractography using FSL's bet2 functionality (Smith, 2002). Masks from three participants were manually-edited in order to remove excess non-brain material.

White matter microstructure modelling (DTI). In order to investigate advanced microstructural properties of white matter, the diffusion tensor (DTI) model was fit to the preprocessed, acpc-aligned dMRI data using FSL's dtifit functionality . For white matter tract profiles, the default parameters of $d$ tifit were used and the $b=1000$ shell was chosen for fitting. However, for mapping of the DTI measures to the cortex, both the $b=1000$ and $b=2000$ shells were used, kurtosis was calculated, and the sum of squared errors was outputted following the parameters used in (Fukutomi et al., 2018).

White matter microstructure modelling: Neurite Orientation Dispersion and Density Imaging (NODDI). In order to investigate advanced microstructural properties of white matter, the Neurite Orientation Dispersion and Density Imaging (NODDI) (Zhang et al., 2012) model was fit to the multi-shell (i.e. $b=1000,2000 \mathrm{~s} / \mathrm{mm}^{2}$ ) dMRI data via the Accelerated Microstructure Imaging via Convex Optimization (AMICO; https://github.com/daducci/AMICO)toolbox (Daducci et al., 2015). The NODDI model represents the diffusion of water in a given location based on biophysical decay patterns of different tissues (i.e. axons, glial cells, extra-axonal space) based on the following function: $A=(1-I s o V F)(I C V F A i c+(1-I C V F)$ Aec $)+$ IsoV F Aiso, where $\mathrm{A}_{\mathrm{ic}}$ and $\mathrm{A}_{\mathrm{ec}}$ are the normalized signal of the intracellular and extra-ceullar components, respectively. Metrics obtained from the NODDI model include intra-cellular volume fraction (ICVF), which is a measure of neurite density (NDI), orientation dispersion (ODI), a measure of spread or fanning of neurites, and isotropic volume fraction (IsoVF), a measure of CSF water volume fraction. The AMICO toolbox was used in order to significantly speed-up the time necessary to fit the NODDI model by reformulating the NODDI model as a linear system, without sacrificing accuracy (Daducci et al., 2015). 
Before model fitting, the multi-shell dMRI image was linearly aligned to the single-shell, anatomically-aligned dMRI image using the flirt command provided by FSL. For major white matter tract analysis, the isotropic diffusivity parameter $\left(\mathrm{d}_{\text {iso }}\right)$ was set to $3.0 \times 10^{-3} \mathrm{~m}^{2} / \mathrm{s}$ (the rate of unhindered diffusion of water) while the intrinsic free diffusivity parameter $\left(\mathrm{d}_{\| /}\right)$was set to $1.7 \times 10^{-3} \mathrm{~mm}^{2} / \mathrm{s}$. For cortical white matter parcel analyses, the isotropic diffusivity parameter was also set to $3.0 \times 10^{-3} \mathrm{~mm}^{2} / \mathrm{s}$ while the intrinsic free diffusivity parameter was set to $1.1 \times 10^{-3} \mathrm{~mm}^{2} / \mathrm{s}$, which is the optimal value of diffusivity found by Fukutomi \& colleagues (Fukutomi et al., 2018).

White matter microstructure modelling (CSD). The CSD model was fit to the preprocessed multi-shell data utilizing MrTrix3 dwi2fod function across 4 maximum spherical harmonic orders (i.e. Lmax ) parameters $(2,4,6,8)$ (Jeurissen et al., 2014a, 2014b; Tournier et al., 2004). $L_{\max }$ 's 6 and 8 were chosen for subsequent white matter tractography.

White matter microstructure modelling (Tractography). Anatomically-constrained probabilistic tractography (ACT) (Smith et al., 2012) implemented in MrTrix3 (Tournier et al., 2010) was used to generate tractograms on preprocessed multi-shell dMRI data for each participant. A total of 1.5 million was tracked over both $L_{\max } 6$ and 8 . The two tractograms were then combined to create a single tractogram of 3 million streamlines. The step-size was set to $0.2 \mathrm{~mm}$ for both $L_{\max } 6$ and 8 . The minimum length of streamlines was set to $25 \mathrm{~mm}$, and the maximum length was set to $250 \mathrm{~mm}$. A maximum angle of curvature of $35^{\circ}$ was set. The merged tractogram of 3 million streamlines was then used for subsequent white matter tract segmentation and network generation.

White matter microstructure modelling (Segmentation). Sixty one human white matter tracts were segmented using a custom method analogous to white matter query language (Bullock et al., 2019; Wassermann et al., 2016). These tracts include the following: L/R arcuate, frontal aslant, corticospinal tract (CST), contralateral anterior frontal cerebellar tracts, contralateral motor cerebellar tracts, inferior fronto-occipital fasciculus (IFOF), inferior longitudinal fasciculus (ILF), middle longitudinal fasciculus-angular gyrus (MDLF-ang) and- superior parietal lobule (MDLF-spl) components, motor cerebellar tracts, occipital cerebellar tracts, superior longitudinal fasciculus components $1 \& 2$ and 3 (SLF-1\&2, SLF-3), temporo-parietal connection, thalamic cerebellar tracts, uncinate, vertical occipital fasciculus (VOF), Baum's and Meyers' loops, cingulum, frontal thalamic tracts, motor thalamic tracts, parietal arcuate (pArc), parietal thalamic tracts, spinothalamic tracts, and temporal thalamic tracts. The callosal tracts, including anterior frontal, forceps major, forceps minor, middle frontal, and parietal corpus callosum, are also included. We used an empirically-documented categorization scheme that grouped major white matter tracts that have been historically associated with a variety of functional domains and behaviors (Schmahmann and Pandya, 2006) (Results: Figure 3a). Specifically, tracts with terminations that connected multiple regions of cortex were classified as associative. Tracts with terminations in cortex and in subcortical structures were classified as projection. Finally, tracts that crossed hemispheres, including the callosal tracts, were classified as commissural.

White matter microstructure modelling: Tract profile generation. Tract profiles (Yeatman et al., 2012) for each NODDI (i.e. NDI, ODI, ISOVF) and DTI (i.e. FA, MD, AD, RD) parameter estimate were generated by estimating the "core" representation of each tract, resampling and partitioning each streamline into 200 equally-spaced nodes, applying a gaussian weight to each streamline based on the distance away from the "core", and then obtaining the weighted average metric at each node. This was performed using MATLAB code utilizing the dtiFiberGroupPropertyWeightedAverage command provided by VISTASOFT developed into a brianlife.io app (brainlife.app.361). In order to avoid partial-voluming effects and to cleanly separate tracts from neighboring gray matter, we removed the first and last 10 nodes from the tract profiles for our white matter tract analyses.

Averages were then computed for each tract, along the remaining 180 nodes, averaged over each group, and were displayed as group averaged Tract Profiles (Yeatman et al., 2012) for group comparisons (Results: Fig. 2).

White matter microstructure modelling: Tract statistics: length and volume. The mean length and volume of each tract were computed using MatLab code designed to quantify a number of tract properties, which has been developed into a brainlife.io app (brainlife.app.189). In order to compute the average streamline length for a given tract, we first iteratively computed the length of each individual streamline composing the given tract. Because streamlines are represented by an ordered sequence of nodes placed in three dimensional space, this was achieved by computing the Euclidean distance (across all three dimensions) between each adjacent pair of nodes, and then summing, to give the three-dimensional distance between all adjacent nodes in a specific streamline. This streamline-specific vector of internode distances was then summed (for each individual streamline), resulting in the total length of the given streamline. The resultant vector of streamline lengths (for the tract in question) was 
then averaged, resulting in the average streamline length of the tract. Volume was computed as the binarized sum of the number of $1 \mathrm{~mm}^{3}$ voxels containing at least one node from a given tract's streamlines.

Cortical and subcortical white matter mapping. DTI and NODDI measures were mapped to each participant's cortical white matter parcels following methods found in Fukutomi and colleagues (Fukutomi et al., 2018) using functions provided by Workbench Command. First, mid-thickness surfaces between the cortical pial surface and white matter surface provided by the Freesurfer segmentation were computed using the wb_command -surface-cortex-layer function provided by Workbench command. A Gaussian smoothing kernel (FWHM $=\sim 4 \mathrm{~mm}$, $\sigma=5 / 3 \mathrm{~mm}$ ) was applied along the axis normal to the surface, and DTI and NODDI measures were mapped using the wb_command-volume-to-surface-mapping function. Freesurfer was used to map the average NODDI parameter estimates to subcortical white matter parcels. NODDI parameter estimates for each segmented cortical and subcortical white matter parcel were extracted and averages for each parcel were computed for each participant. Group average and standard errors (SE) for each parcel were computed.

Signal-to-noise ratio (SNR) calculation. Signal-to-noise ratio (SNR) was calculated on the normalized preprocessed dMRI image using DIPY's workflow for calculating SNR (Descoteaux et al., 2011; Garyfallidis et al., 2014; Jones et al., 2013). First, a mask of the corpus callosum was generated from the dMRI image. The mean signal in each direction (i.e. X, Y, Z) and the dwi images without a diffusion gradient (i.e. b0 images) were then calculated inside the corpus callosum mask. Next, the standard deviation of the signal in the background of the image outside of the brain was calculated. The ratio between the mean signal in the corpus callosum mask for each direction and the standard deviation of the noise was computed for each subject and used for statistical analyses (see Methods: Statistical analyses). We reported the value found in the b0 image, representing the best possible SNR of the data.

Statistical analyses. Non-parametric statistical tests of the difference between the means and estimation of the confidence intervals. We performed a bootstrap test of the difference between two means (see (Pestilli et al., 2011)). We will describe one example test for a single NODDI measure, NDI, and the white matter tracts. The same approach applies to all other measures for NODDI and DTI and for cortical and subcortical parcels as well as for all other group comparisons (football - cross country, football - non-athlete, and cross country - non-athlete). First, we assumed that $\mathrm{HO}$ is true (i.e. no differences between groups) to test for a significant difference in NDI measures between groups. To do so, the averaged NDI for each white matter tract, for each group was collected ( $n=61$ tracts). This produced two distributions of NDI one for the first and one for the second group of subjects,

$G_{1}$ and $G_{2}$ both of size $n$. We then assumed $H_{0}$ true by combining the two groups into a union vector: $G_{H_{0}}=G_{1} \cup G_{2}$. After that, we resampled with replacement two samples 10,000 times from $G_{H_{0}}$, randomly assigned one sample to a $G_{1}$ and the other to $G_{1}$ and repeated this process so to build an $n \times 10,000$ set for $G_{1}^{\prime}$ and an $n \times 10,000$ set for $G_{2}^{\prime}$. The difference between $G_{1}^{\prime}$ and $G_{2}^{\prime}$ was commuted for the 10,000 samples. This process generated a distribution of differences $D_{H_{0}}$ with mean 0 , implementing the null hypothesis. The empirical difference obtained $D_{e}=G_{1}-G_{2}$ was then compared with $D_{H_{0}}$ by computing the two-tailed percentiles that $D_{e}$ represented in $D_{H_{0}}$, after transforming the percentile to probability by dividing by 100 , we reported this value in all our tests. If the value was less than 0.05 or less when corrected for multiple comparisons a difference between two samples was deemed statistically significant. A strict Bonferroni correction was applied for most of our tests so that $p$ used for significance was effectively 0.0023 (0.05 / (7 measures (DTI + NODDI) * 3 group comparisons)). Confidence intervals and effect sizes were also computed via bootstrap. The subject's in each group were resampled with replacement 10,000 times. An individual participant's NODDI or DTI data for each structure within a tissue type were organized into a vector, and the average difference across all structures and participant group comparisons were recorded. The confidence interval around the difference was identified as the 2.5 and 97.5 percentile group difference values. Effect sizes were calculated as the average participant group difference in each DTI or NODDI measure divided by the pooled variance of the two groups across all structures within a tissue-type. The average effect sizes across NODDI or DTI measures was then computed and used to rank the structures in Results: Figures 3(a,b), 5(a,b), and 7(a,b) and are reported in Supplementary Tables 1, 3, and 4.

Demographics, brain size, body size. We performed multiple one-way ANOVAS between our groups utilizing the python repository statsmodels' ols function to test for differences in the following: age, body weight, SNR, average gray-matter cortical thickness, total brain volume, gray-matter cortical volume and white matter volume. Bonferroni multiple comparisons correction was performed, and all reported $p$-values were significantly below a corrected $p<0.0083$ (0.05 / 6 measures). 
Structure size versus NODDI parameter estimate. We computed the regression between group average NODDI and DTI parameter estimates and various macro-measures of segmented structures, including log-volume and thickness for cortical white matter parcels, and log-volume and length for major white matter tracts. The log-transformed data was used to account for the large range in parameters values across segmented structures. Significant effects of macro-structure on microstructure were tested utilizing MATLAB's aoctool.

\section{Results}

\section{Microstructural estimates in the human major white matter tracts.}
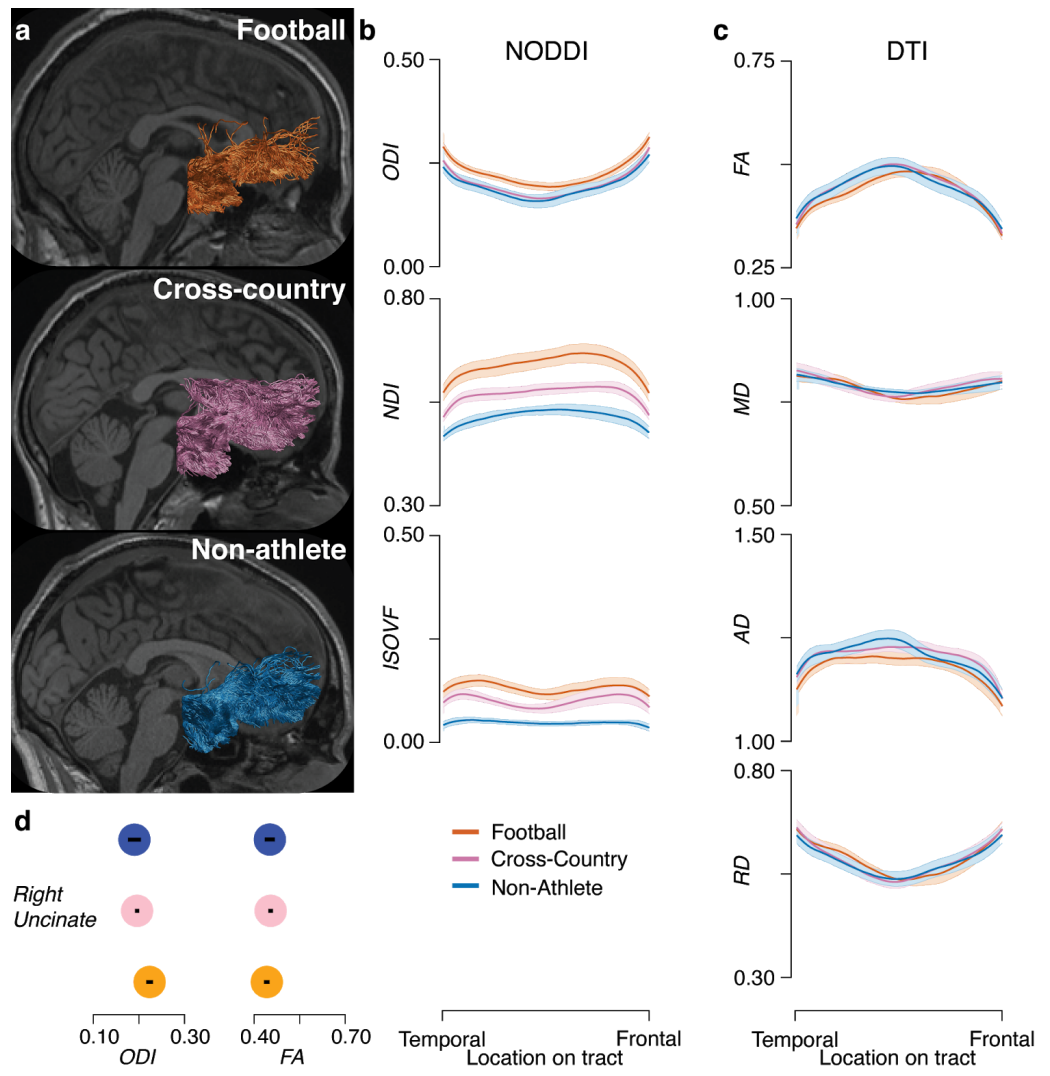

Figure 2. Example tract profiles of one major-white matter tract. a. Sixty one white-matter tracts, such as the Right Uncinate depicted, were segmented in each participant (orange: football players, pink: cross country runners, blue: non-athlete students) using a cloud computing white matter segmentation application publicly available at brainlife.io (blapp. 188). b. Tract profiles for the Right Uncinate illustrating average group values for orientation dispersion (ODI, top), neurite density (NDI, middle), and isotropic volume fraction (ISOVF, bottom; bl.app.361). Profiles were averaged within each group (i.e. orange: football players, pink: cross country runners, blue: non-athletes). Error bars \pm 1 SE. c. Tract profiles for the Right Uncinate illustrating average group values for fractional anisotropy (FA, top), mean diffusivity (MD), axial diffusivity (AD), and radial diffusivity (RD; bottom). Profiles were averaged within each group (i.e. orange: football players, pink: cross country runners, blue: non-athletes). Error bars \pm 1 SE. d. Group average tract ODI and FA computed from tract profiles in b,c. Error bar $\pm 1 \mathrm{SE}$.

Figure 2a shows one example white matter tract, the Right Uncinate, segmented in one representative individual from each group. The tract profiles reporting the NODDI parameters (ODI, NDI, and ISOVF) and DTI parameters (FA, MD, AD, RD) for the parietal corpus callosum example were averaged across participants in each group and are shown in Figure 3b,c. Group averages and SE for ODI and FA across the entire track were computed from the tract profiles in Figure 3b,c, and are shown in Figure 3d.

Collegiate athletes were found to have higher NODDI parameter estimates across the majority of the parietal corpus callosum (Figure $\mathbf{2 b}$ ). Across the majority of the segmented tracts there was an orderly arrangement of NODDI parameters with football players having larger values, cross country runners being in the middle, and non-athletes having smaller values (Figure 3b). Via bootstrapping analyses (Figure 4), football players were found to have significantly higher NDI (difference: 0.048 ; $\mathrm{p}$-value: 0.0001 ; $\mathrm{Cl}: 0.023-0.073$ ) values than cross country runners. Football players were also found to have significantly higher ODI (difference: 0.020; $p$-value: 0.0019; Cl: 0.014-0.026), NDI (difference: 0.068; p-value: 0.0000; Cl: 0.045-0.091), and ISOVF (difference: 0.046; p-value: $0.0000 ; \mathrm{Cl}: 0.036-0.056)$ than non-athletes. Cross country runners were found to have significantly higher ISOVF (average difference: 0.028; p-value: 0.0007; Cl: 0.019-0.036) than non-athletes. 
DTI parameter estimates proved to be less orderly in the differences between groups across the segmented tracks (Figure 3c). No DTI measures were identified as significantly significant ia bootstrapping analyses (Figure 4), after Bonferroni correction.
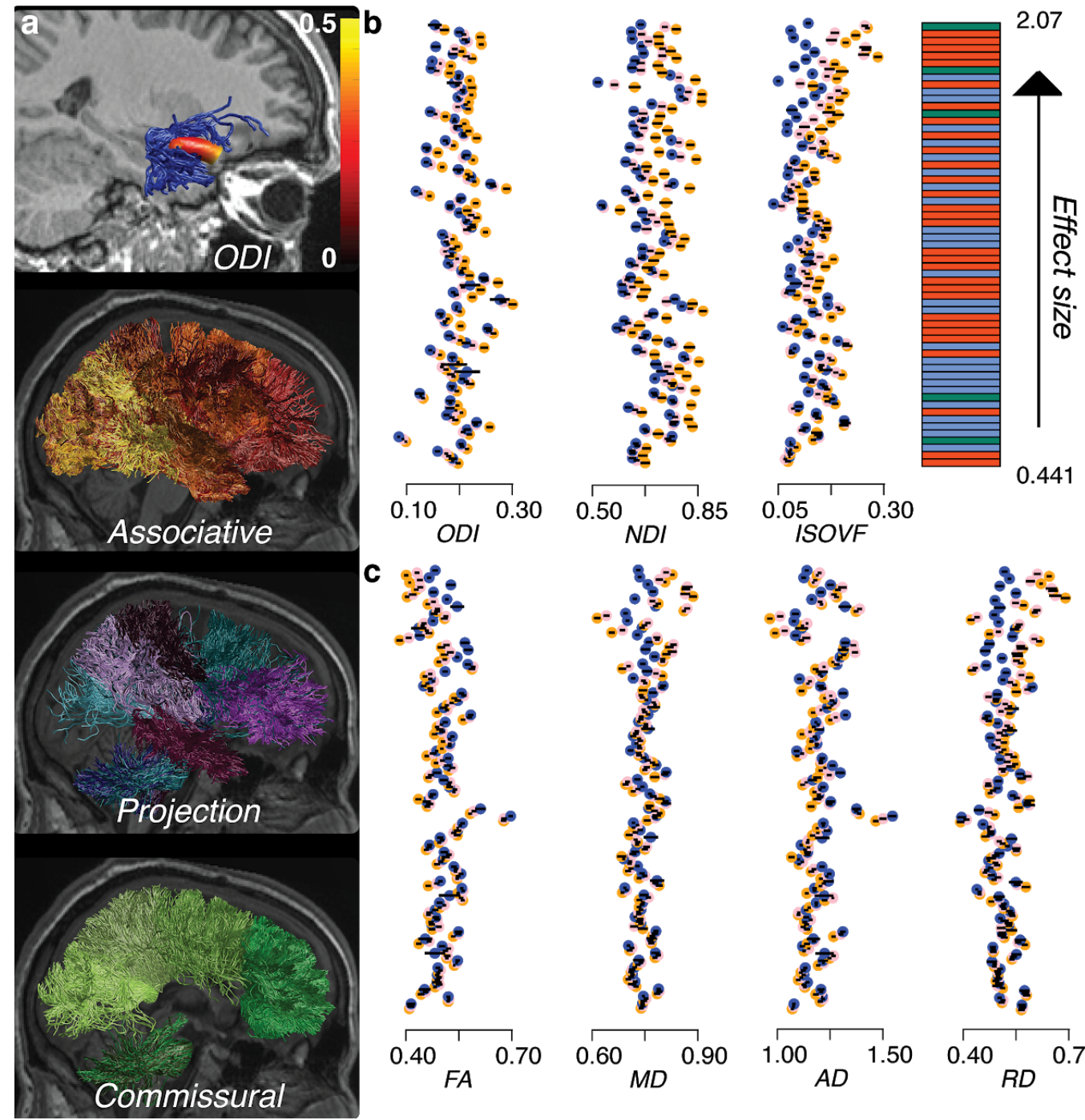

\section{Rank Effect Size

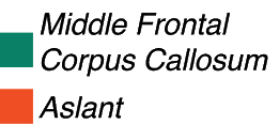 \\ Aslant}

Cingulum

ILF

Anterior Frontal

Corpus Callosum

Anterior Frontal

Cerebellar

Uncinate

Contralat. Anterior

Frontal Cerebellar

Arcuate

Forceps Minor
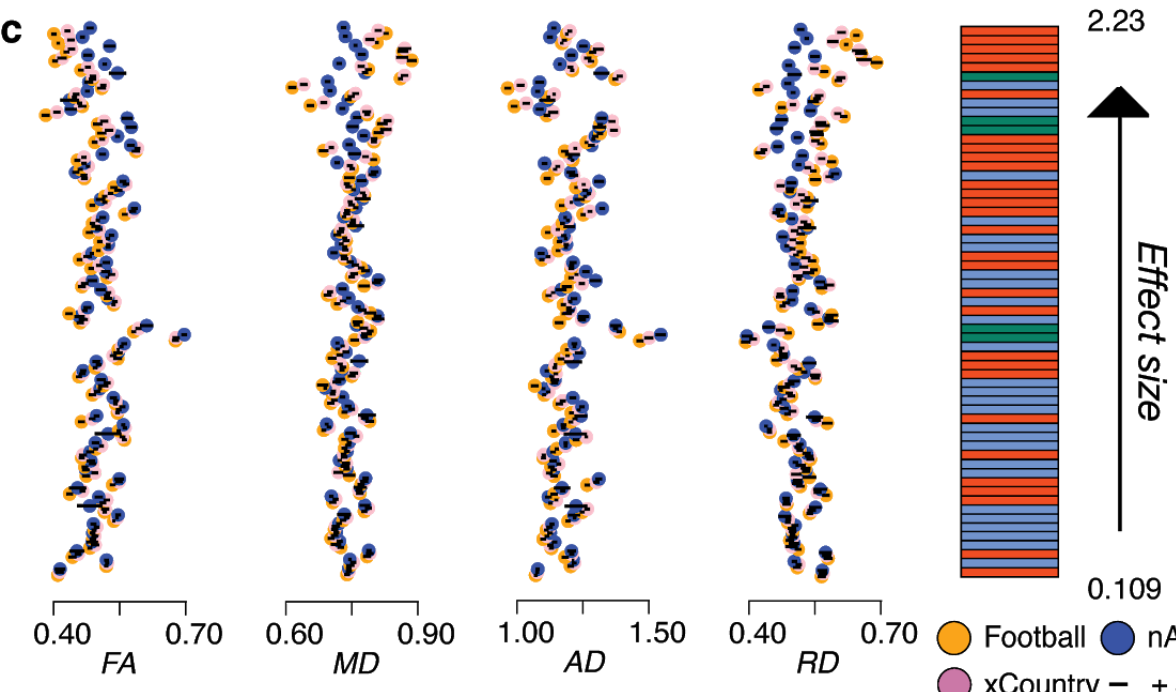

Football $\bigcirc$ nAthlete
xCountry - \pm SEM

Figure 3. Major white-matter tract microstructure between participant groups. a. Top Left: ODI overlayed on a representation of the Right Uncinate core fiber in one participant. Top Right and Bottom: Tract segmentations were categorized by functional domains (i.e. Associative - red, Projection - blue, Callosal - green; See Supplemental Table 1 for the explanation of domains). b. Average group NODDI white matter estimates (ODI, NDI, and ISOVF) values for all major white matter tracts (orange: football players, pink: cross country runners, blue: non-athletes). Error bars \pm 1 SE. Tracts were then arranged in order of average effect size across all comparisons (football - cross country, football-non-athletes, cross country - non-athletes) and NODDI measures. The tracts with the largest average effect size for NODDI measures are listed (right). c. Average group DTI white matter estimates (FA, MD, AD, and RD) values for all major white matter tracts (orange: football players, pink: cross country runners, blue: non-athletes). Error bars $\pm 1 \mathrm{SE}$. Tracts were arranged in order of average effect size across all comparisons (football - cross country, football-non-athletes, cross country non-athletes) and DTI measures. 
a

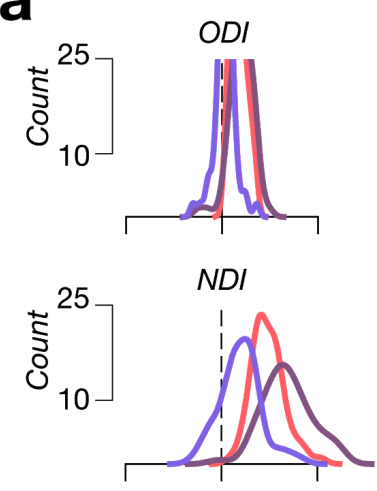

$\left.\stackrel{\mathrm{D}}{5}_{10}^{25}\right]$ b
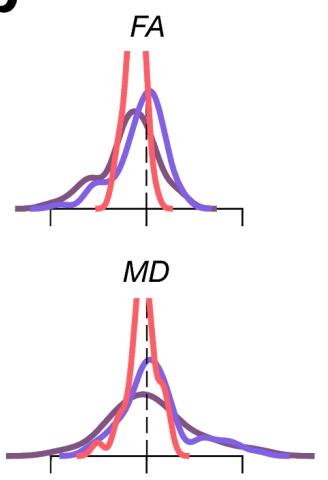

$A D$
Figure 4. Major white-matter tracts show microstructure differences between participant groups. a. Average group differences between participant groups across all tracts for ODI (top), NDI (middle), and ISOVF (bottom) . b. Average group differences between participant groups across all tracts for FA (top), MD, AD, and RD (bottom). Histograms were computed over the estimates across 61 white matter tracts and smoothed using a kernel density estimate (KDE) computed with seaborn's distplot function (Waskom and Others, 2020).

\section{Microstructural estimates of cortical white matter.}

Collegiate athletes were found to have higher NODDI parameter estimates across a majority of cortical regions (Figure 5b). In a similar fashion to the white matter tract analysis, football players have larger NODDI parameter estimates, cross country runners are in the middle, and non-athletes have small NODDI parameters across the 8 cortical regions. Via bootstrapping analyses (Figure 6), football players were found to have significantly higher ODI (difference: 0.016; p-value: 0.0001; Cl: 0.004-0.027), and NDI (difference: 0.030; p-value: 0.0000; Cl:

$0.015-0.043$ ) values than cross country runners. Football players were also found to have significantly higher ODI (difference: 0.029; $p$-value: 0.0000; Cl: 0.015-0.043), NDI (difference: 0.028; $p$-value: 0.0000; Cl: -0.022-0.020), and ISOVF (difference: 0.036; p-value: 0.0000; Cl: 0.014-0.058) than non-athletes. Cross country runners were found to have significantly higher ODI (difference: 0.013; p-value: 0.0006; Cl: 0.0010 .026 ), and ISOVF (difference: 0.028 ; p-value: 0.0004 ; $\mathrm{Cl}: 0.007-0.050$ ) than non-athletes.

DTI parameter estimates proved to be less orderly in the differences between groups across the segmented cortical regions (Figure 5c). Via bootstrapping analyses (Figure 6), football players were found to have significantly lower FA (difference: -0.013 ; $p$-value: 0.0000 ; Cl: $-0.026--0.001$ ) than non-athletes. Cross country runners were found to have significantly lower FA (difference: -0.016 ; p-value: 0.0000 ; Cl: $-0.028--0.005$ ), and higher RD (difference: 0.044; $p$-value: 0.0008; Cl: 0.016-0.072) than non-athletes. No other DTI measures identified statistically significant group differences after Bonferroni correction. 

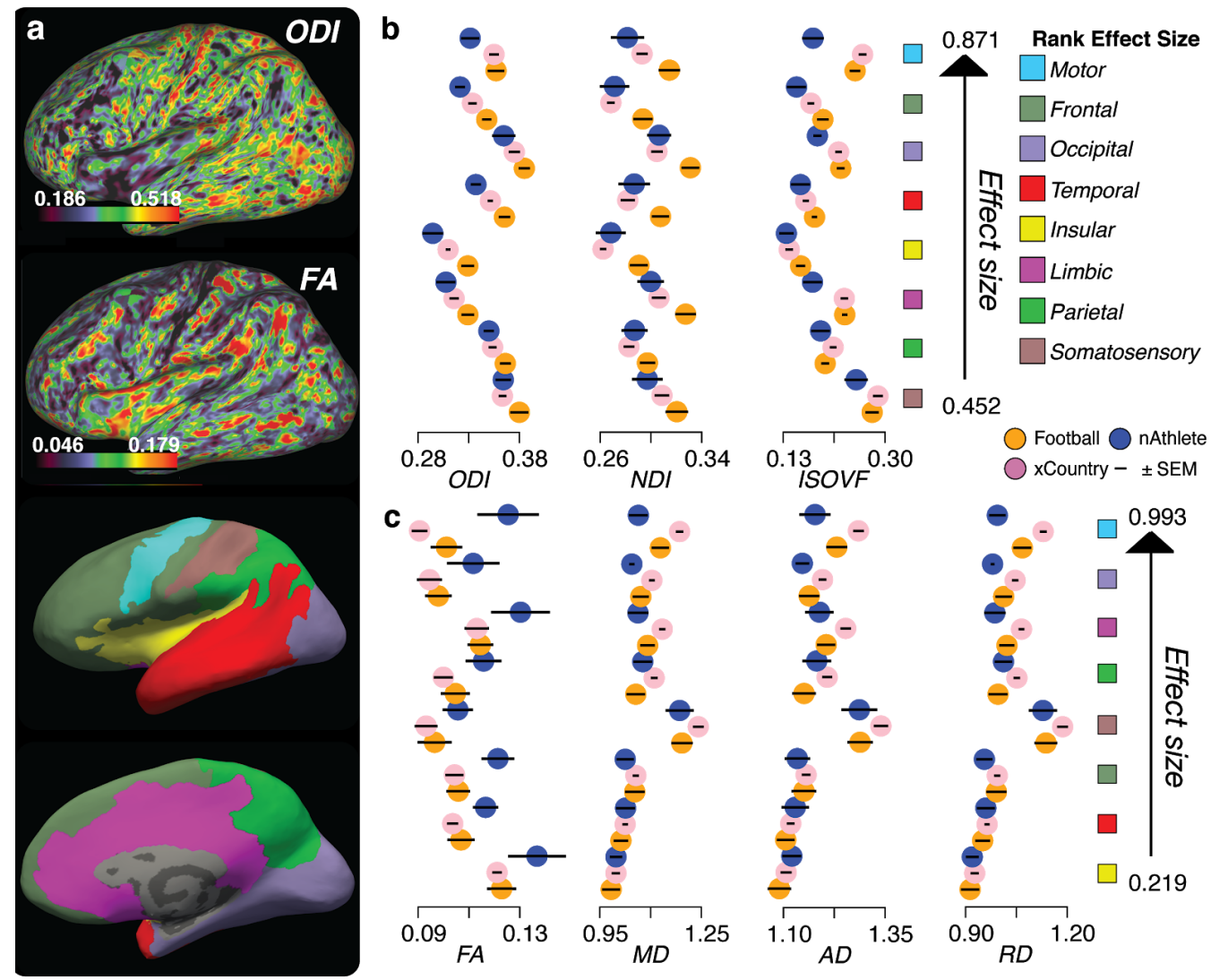

Figure 5. Comparing cortical white-matter microstructure between participant groups. a. Top. Cortical white matter ODI and FA surface maps in one representative subject(Fukutomi et al., 2018) generated using brainlife.app.0 and brainlife.app.379. Bottom. Cortical regions-of-interest (ROIs) used for the analyses. b. Average group NODDI white matter microstructure estimates (ODI, NDI, and ISOVF) for the ROIs in a. Domains were arranged in order of average effect size across all comparisons (football - cross country, football-non-athletes, cross country - non-athletes) and NODDI measures. The domains with the largest average effect size for NODDI measures are listed (right). Legend: football players (orange), cross country runners (pink), non-athletes (blue); error bars show $\pm 1 \mathrm{SE}$. c. Average group DTI white matter microstructure estimates (FA, MD, AD, RD) for the ROls in a. Domains were arranged in order of average effect size across all comparisons (football - cross country, football-non-athletes, cross country - non-athletes) and DTI measures. Legend: football players (orange), cross country runners (pink), non-athletes (blue); error bars show \pm 1 SE. Supplemental Table 2 reports the mapping between the Freesurfer parcels and ROls in $\mathbf{a}$. 


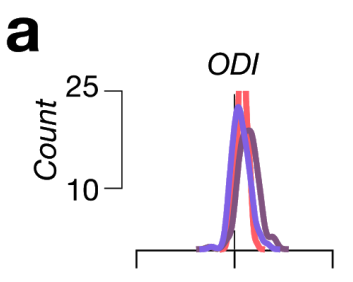

b
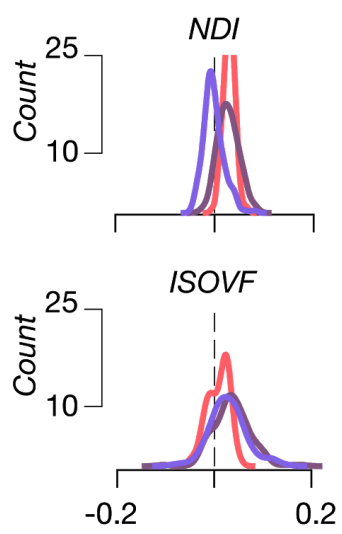

Football -

$\square$ Cross-country Football -

$\square$ Non-athlete Cross-country Non-athlete
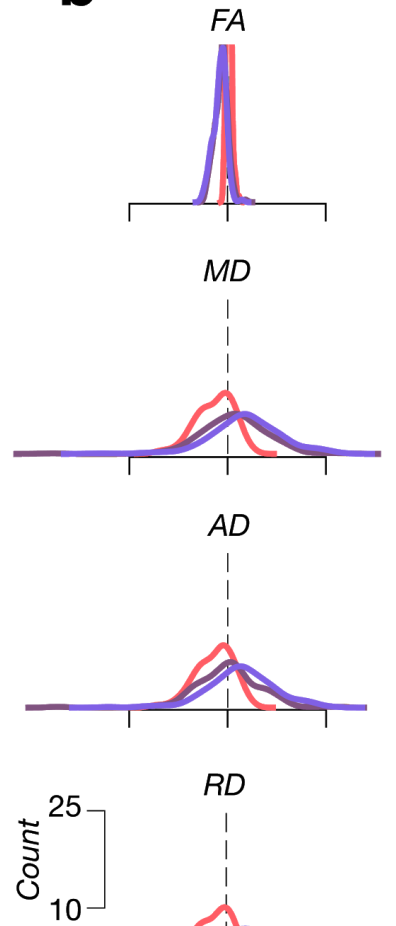

$R D$

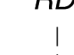

I

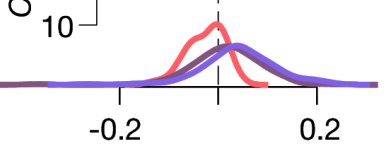

Figure 6. Cortical white matter parcels show microstructural differences between participant groups. a. Average group differences between across all cortical parcels for ODI (top), NDI (middle), and ISOVF (bottom). b. Average group differences between participant groups across all cortical parcels for FA (top), MD, AD, and RD (bottom). Histograms were computed over the estimates across 148 cortical structures and smoothed using a kernel density estimate (KDE) computed with seaborn's distplot function (Waskom and Others, 2020).

\section{Microstructural estimates of subcortical white matter.}

Only minor differences were found in subcortical white matter tracts with collegiate athletes having non-significant higher NODDI parameter estimates across a majority of cortical regions (Figure 7b). A bootstrapping analysis (Figure 8) demonstrated no group differences in any of the NODDI or DTI measures after Bonferroni correction. 

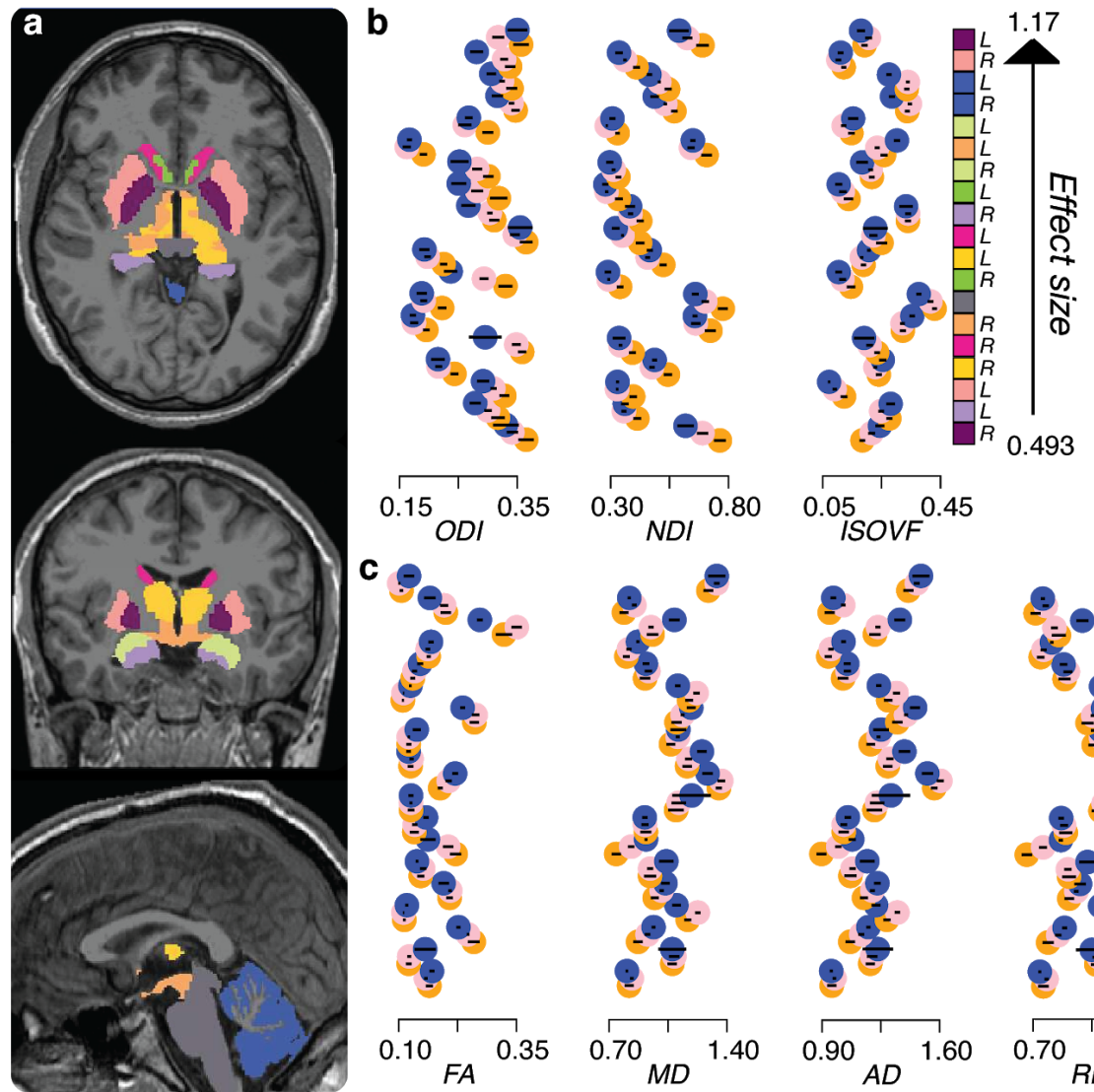

Rank Effect Size
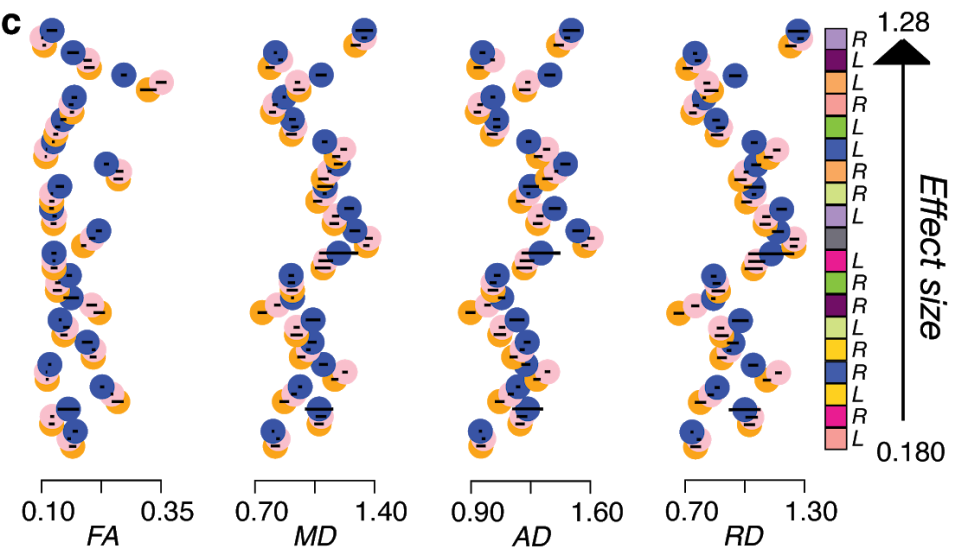

Figure 7. Comparing subcortical white-matter microstructure between participant groups. a. Subcortical white matter parcels used for the analyses in one representative subject. b. Average group NODDI white matter microstructure estimates (ODI, NDI, and ISOVF) for the ROls in a. Legend: football players (orange), cross country runners (pink), non-athletes (blue); error bars show \pm 1 SE. Subcortical parcels were arranged in order of average effect size across all comparisons (football - cross country, football-non-athletes, cross country - non-athletes) and NODDI measures. The parcels with the largest average effect size for NODDI measures are listed (right). c. Average group DTI white matter microstructure estimates (FA, MD, AD, RD) for the ROls in a. Legend: football players (orange), cross country runners (pink), non-athletes (blue); error bars show \pm 1 SE. Subcortical parcels were arranged in order of average effect size across all comparisons (football - cross country, football-non-athletes, cross country - non-athletes) and DTI measures. 


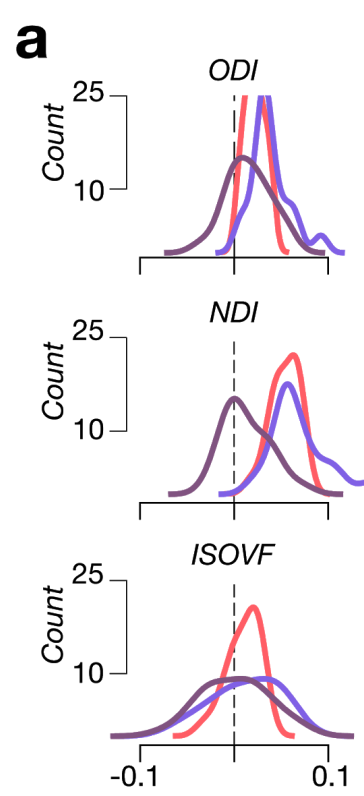

b
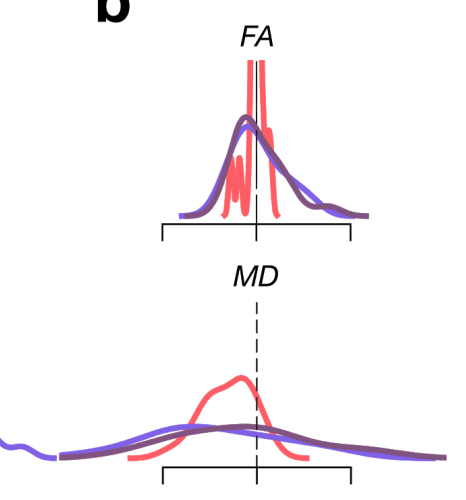
Football -
Cross-country Football -
$\square$ Non-athlete
Cross-country -
Non-athlete

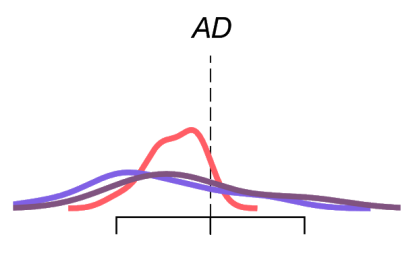

$R D$

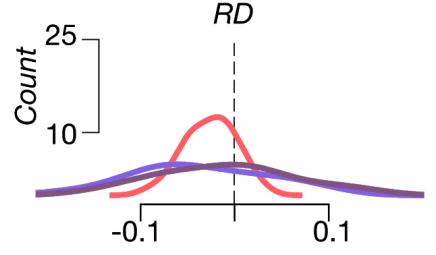

Figure 8. Subcortical white matter parcels show little microstructural differences between participant groups. a. Average group differences between participant groups across all subcortical parcels for ODI (top), NDI (middle), and ISOVF (bottom) b. Average group differences between participant groups across all subcortical parcels for FA (top), $\mathrm{MD}, \mathrm{AD}$, and RD (bottom). Lines represent the kernel density estimate (KDE) computed with seaborn's distplot function. Histograms were computed over the estimates across 19 subcortical structures and smoothed using a kernel density estimate (KDE) computed with seaborn's distplot function (Waskom and Others, 2020).

\section{Brain volume does not explain white matter microstructural property differences despite differences in body mass.}

Football players, on average, have a different body composition and size as compared to cross country runners and non-athlete students $(F(2,39), p<0.0001$; Figure 9e). Because of this, we tested whether the differences in microstructural tissue properties may be due to differences in overall brain size. To test this, we obtained the brain volume, cortical volume, white matter volume, and cortical thickness measures from each participant using Freesurfer (Methods: Anatomical data (T1w) processing) and computed one-way ANOVAs between our groups for each measure (Bonferroni corrected $p<0.01$ ). We found no significant difference between our groups in terms of either brain volume (Figure 9a), cortical volume (Figure 9b), white-matter volume (Figure 9c), or cortical thickness (Figure 9d).
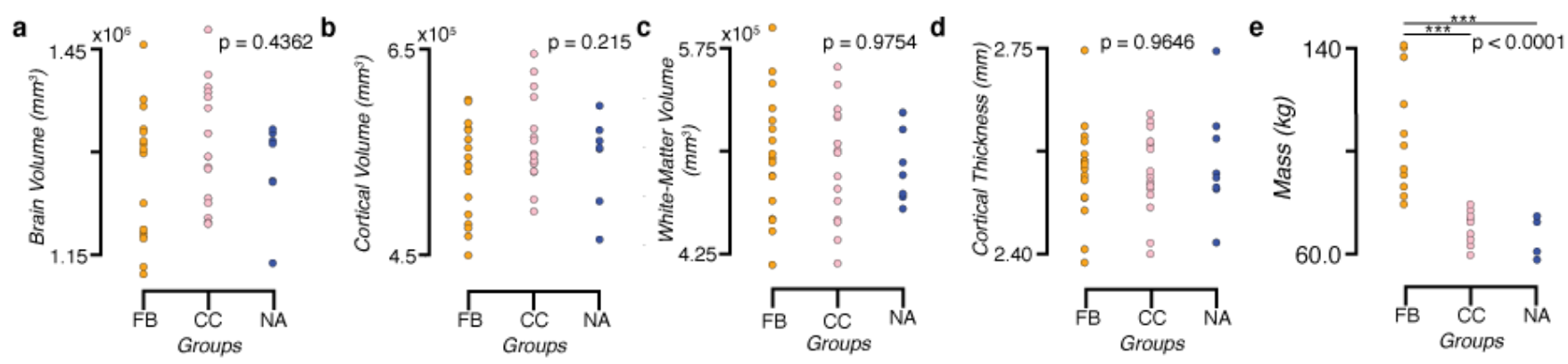

Figure 9. Total brain volume, gray-matter cortical volume, white matter volume, and average gray-matter cortical thickness show no differences between groups despite differences in body mass. Group distributions of total brain volume (a), cortical volume (b), white matter volume (c), and average cortical thickness (d). One-way ANOVAs showed no significant differences between the groups in these measures. A significant difference was observed between the mass (e) of football players and the two other groups $(p<0.005$ Bonferroni corrected). 


\section{Discussion}

This study characterized group differences among football, cross country athletes, and matched non-athlete controls. Measurements were obtained in cortical and deep white matter as well as in several subcortical structures. The results demonstrated widespread differences in white matter microstructure in cortical white matter and major white matter tracts between collegiate football players, cross country runners and non-athletes.

Microstructural differences were better identified using the NODDI model as opposed to the DTI model, with a majority of the measures from NODDI being able to identify significant differences between our three groups while only FA and RD were able to identify any differences. This result is consistent with previous investigations into the discriminative power of DTI and NODDI across a wide range of populations (By et al., 2017; Churchill et al., 2018; Colgan et al., 2016; Mitchell et al., 2019; Schneider et al., 2017). This study extended previous studies by investigating alterations across the entirety of the brain in athletes and non-athletes using both the standard DTI model and a more advanced NODDI model. The observed differences between athletes and non-athletes in white matter microstructural properties, including increased NDI, ODI, and ISOVF, may be due to a number of potential biological or biomechanical factors. An increase in NDI could be related to exercise-associated increases in synaptogenesis and dendritic spine density (Hötting and Röder, 2013), or, alternatively, alterations in ionic and metabolic balance leading to axonal swelling associated with neuroinflammatory mechanisms (Pettus et al., 1994; Skinner et al., 2015; Z. Wang et al., 2019), including mitochondrial clearage dysfunction (Errea et al., 2015; Lee et al., 2020; Powers et al., 2020). Increased ODI may also reflect increased neuroplastic alterations as well as increased proliferation of microglia and other neuroinflammatory-related cellular structures (Yi et al., 2019). Increased ISOVF is typically associated with mechanisms elevating free water, including neuroinflammation (Fick et al., 2017; Suzuki et al., 2017). Overall, the corresponding increases in NDI, ODI, and ISOVF may be reflective of neuroinflammatory mechanisms related to differences in stress-levels and peripheral inflammation between athletes and non-athletes. This hypothesis is further supported by the lack of reliable differences identified with the DTI model, which is not as effective at identifying tissue alterations due to neuroinflammatory mechanisms (Yi et al., 2019). However, to fully understand the underlying pathology of the observed differences requires histological investigations that are beyond the scope of this investigation.

Identifying direct interpretations of the white matter microstructural properties derived from diffusion MRI models, however, is challenging(Rokem et al., 2017; Wandell, 2016). The most widely used model, diffusion tensor imaging model or DTI, has limitations, most notably the inability to accurately model regions with crossing fibers ((Jeurissen et al., 2013). More recent models attempt to provide parameters that also characterize the tissue in the presence of crossing fibers. Another issue of the DTI model is its proven inability to identify alterations in glial cell infiltration and activity (Yi et al., 2019). Measuring signals indirectly related to glial cells infiltration is critical in order to identify and characterize the potential effects of chronic stress and inflammation from elite athletics (Figure 1e). NODDI addresses these issues by exploiting multishell dMRI data (Frank, 2002) to characterize both axonal and dendritic (i.e. neurite) density and orientation by separately modeling the anisotropic component (hindered and restricted diffusion provided by myelin and neurites) and isotropic component (free-moving water). These separate models can then provide information regarding the density and orientation of neurites in tissue, and potentially the infiltration of glial and inflammatory processes. NODDI parameter estimates provide measures with different degrees of sensitivity to the various components of the white matter tissue microstructure. For example, differences in ODI can be attributed to a variety of biophysical or biomechanical factors including the formation of new spines, alterations to axonal diameter (Alexander et al., 2010; Zhang et al., 2011), myelin density (N. Wang et al., 2019), microglial density (Yi et al., 2019), alterations to the patterns of crossing fibers (Sato et al., 2017; Schilling et al., 2018), and gross alterations to the orientation of neurites that could arise from repetitive head impacts (Figure 1e). Changes in NDI can be interpreted as changes in the density of myelinated neurites (Zhang et al., 2012) but have also been associated with hyper-phosphorylated tau-deposition in the cortex (Colgan et al., 2016), axonal beading (Skinner et al., 2015), and alterations in ionic balance (Z. Wang et al., 2019), mitochondrial density and shape (Errea et al., 2015; Lee et al., 2020)), and myelin density (Luo et al., 2018; Sepehrband et al., 2015; N. Wang et al., 2019). Finally, ISOVF relates to changes in intra-voxel fluid content (Zhang et al., 2012) and can be potentially related to changes in microscopic fluid content for example due to inflammatory processes (Fick et al., 2017; Suzuki et al., 2017) such as those observed following head impacts. In sum, the NODDI model allows us to evaluate various microstructural parameters with different biological interpretations. To date, it is agreed that it is difficult to uniquely interpret the differences in any of the parameters as a reduction or increase in brain tissue quality. Nonetheless, the parameters can be used for predictions or 
correlated with phenotypic characteristics of the study participants to clarify the putative effects -beneficial or deterimental- of sports participation on the brain white matter tissue.

Relation to previous investigations. A variety of previous investigations into the effects of sports participation, repetitive head impacts, and white matter tissue properties of athletes have used the diffusion tensor (DTI) model (Bahrami et al., 2016; Basser et al., 1994a; Bazarian et al., 2014; Burzynska et al., 2016; Chang et al., 2015; Chun et al., 2015; Churchill et al., 2017a, 2017b; Davenport et al., 2016a, 2016b, 2014; Deng et al., 2018; Duru and Balcioglu, 2018; Gajawelli et al., 2013; Gong et al., 2018; Hänggi et al., 2015, 2010; Jäncke et al., 2009; Koerte et al., 2012; Kuzminski et al., 2018; Lao et al., 2015; Lefebvre et al., 2020; Marchi et al., 2013; Mayinger et al., 2018; McAllister et al., 2014; Merchant-Borna et al., 2016; Myer et al., 2018, 2016a, 2016b; Park et al., 2015; Rubin et al., 2018; Saghafi et al., 2018; Schlaffke et al., 2014; Schranz et al., 2018; Slobounov et al., 2017; Sollmann et al., 2018; Stamm et al., 2015; Strauss et al., 2020; Yuan et al., 2018). The studies investigating the effects of elite sports participation, especially collision-prone sports, commonly report lower fractional anisotropy (FA) and higher mean diffusivity (MD) between athletes and non-athletes (Bahrami et al., 2016; Bazarian et al., 2014; Chang et al., 2015; Chappell et al., 2006; Deng et al., 2018; Gong et al., 2018; Hänggi et al., 2010; Kuzminski et al., 2018; Lefebvre et al., 2020; Mayer et al., 2017; Rubin et al., 2018). However, this trend is not reported in all investigations, with some finding the exact opposite trend (Churchill et al., 2017b; Gajawelli et al., 2013; Hänggi et al., 2015; Mayinger et al., 2018). Of these studies investigating these effects, results commonly differ. These differing results depend on a number of factors, including sport and competition-level of the athletes studied, the inclusion criteria for non-athlete controls, time points at which athletes were scanned, and methodology employed(Schneider et al., 2019). Of the investigations investigating white matter tissue differences between collision, non-collision, and non-athletes, Lefebvre et al (Lefebvre et al., 2020) employed the most similar study design to this using only the DTI model, however key differences are important to note. They reported higher FA in non-contact sports athletes as compared to both contact and non-athletes in segments of the corpus callosum (CC) and the corticospinal tract (CST). However, they used different athlete groups for their collision and non-collision sports types, and the athletes included were not competing at a D-I level. These results are in contrast to the direction of differences observed in this study, with non-athletes tending to have higher FA than both athlete groups. The inconsistency in results using DTI further speaks to the need for advanced microstructural biomarkers such as the neurite orientation dispersion density imaging model - NODDI (Zhang et al., 2012).

To the authors' best knowledge, there is only one previous investigation into the effects of repetitive head impact exposure and microstructural properties derived using the NODDI model (Mayer et al., 2017). Mayer and colleagues(Mayer et al., 2017), investigated the effects of repetitive head impact exposure in a group of mixed-martial arts athletes and compared NODDI-derived microstructural properties to those of non-contact physically-active athlete controls. The authors did not use tract-profiles nor cortical and subcortical white matter mapping as done in the current study. They used a voxel-wise approach and reported that NDI, ODI, and ISOVF were all higher in mixed-martial arts participants in a variety of brain structures, including the corpus callosum, internal and external capsule, and the SLF. These results are consistent with our findings. The correspondence in the results of these two studies provides evidence that NODDI may be useful in differentiating the effects of elite sports participation and $\mathrm{RHI}$ on white matter tissue structure. This differentiation is vital for future biomarker investigations into the potentially detrimental effects of $\mathrm{RHI}$ on brain tissue structure.

A secondary observation in our study regards the brain volumes observed across our three groups. Specifically, no significant differences between our three groups were observed in total brain matter volume, white matter volume, gray matter volume, or gray matter cortical thickness despite an observed difference in body mass (Figure 9). This is of particular interest as previous investigations into the effects of sports participation, collision-sports participation, and repetitive head impacts have reported differences in brain volumes between groups of interest and controls (Koerte et al., 2015; Tremblay et al., 2018), and the relation between body weight and brain volume (Gunstad et al., 2008). The lack of observed differences in brain volume between groups may be reflective of the effect of timing of observation, as a number of investigations into this link focus on former athletes while we observed athletes while they were still competing. However, this investigation was not designed to fully investigate this link. Future investigations are needed to fully understand the relationship between sports participation, collision-sports participation, and gross brain structure.

Several limitations to the current study exist and will need to be addressed by future research. First, due to the difficulty in collecting participants, our study had a relatively small number of participants and sports. The lack of 
participants reduces the interpretative power and generalization to other sports. For this reason, we openly share all the data, results, and analyses in the hope to contribute to the larger community in repetitive head impact research. Second, we report differences in signal to noise (SNR) across groups (see Supplementary Figure 9k). These differences can in principle affect the reliability of the NODDI model estimates(Daducci et al., 2015), yet, the SNR variation across groups (higher in cross country runners and indistinguishable between controls and football players) disagree with the direction of the effects in microstructural differences we found. Third, our study was limited to male football players in all three groups. This is an important limitation that will need to be addressed by future research to clarify the potential role of sex differences in sports participation, repetitive head impacts, and concussion. Finally, both the DTI and NODDI models have been found to provide biased measurements in gray matter (Fukutomi et al., 2019; Kaden et al., 2016; Lampinen et al., 2017; Novikov et al., 2018). These biases impact the interpretative power of the structural differences between our groups. However, since these biases are common across all of our participants, the differences between groups should still be reliable.

The present study contributes to the larger societal needs to identify the effects of sports participation on the brain tissue by combining anatomically guided methods for brain tissue microstructural mapping (Alexander et al., 2007; Fukutomi et al., 2018; Pedregosa et al., 2011; Pestilli et al., 2014; Rokem et al., 2017; Smith et al., 2012; Takemura et al., 2016; Wandell, 2016; Zhang et al., 2012) across multiple tissue types (deep white matter tracts, cortical white matter, and subcortical white matter) in collision-prone, non-collision-prone, and non-athletes. More specifically, we measured the biological properties of human brain tissue in two elite athlete groups and a control group. We measured athletes from collision (football players) and non-collision sports (cross country runners) and compared them to non-athlete students. We focused our analyses on the microstructural properties of the myelinated brain tissue (i.e. white matter) for two reasons. First, the alterations in myelinated tissue can be used to identify both beneficial and detrimental effects of long-term sports participation, including neuroinflammation and neuroplasticity. Second, diffuse axonal injury and atrophy of myelinated tissue are consistent features found in the brains of those diagnosed with CTE at autopsy (Chappell et al., 2006; Graham et al., 2014; Smith, 2016), and are thought to be precursors to the tau build-up (McKee et al., 2015).

\section{Advancing scientific understanding of elite sports participation and repetitive head impact exposure using} open science methods and data sharing. In addition to advancing the scientific understanding both the effects of participation in elite collegiate athletics and repetitive head impact exposure, we embraced an open science approach and use the recently developed cloud-computing platform brainlife.io to share the full research assets developed for the study - data and reproducible analyses methods (Avesani et al., 2019; Bullock et al., 2019; Pestilli, 2018; Stewart et al., 2015; Towns et al., 2014). This investigation is the first in the field of sports participation, including collision and non-collision sports, examining white matter tissue structure to use a fully-automated open science data processing platform. The brainlife.io platform allows other researchers to reuse the data, derivatives, and analyses methods to replicate or build upon our findings. Due to the difficulties associated with the collection and analysis of data related to sports, including $\mathrm{RHI}$ and TBI, we believe that promoting open sharing of data and methods will become paramount for the success of the scientific enterprise. All of our data, data derivatives, and analyses can be found associated with a single digital record, referenced by https://doi.org/10.25663/brainlife.pub.14. We hope this effort will accelerate the development of understanding regarding the effects of elite sports participation on brain tissue. 


\section{References}

Adams, J.H., Doyle, D., Ford, I., Gennarelli, T.A., Graham, D.I., McLellan, D.R., 1989. Diffuse axonal injury in head injury: definition, diagnosis and grading. Histopathology 15, 49-59.

Adams, J.H., Graham, D.I., Murray, L.S., Scott, G., 1982. Diffuse axonal injury due to nonmissile head injury in humans: an analysis of 45 cases. Ann. Neurol. 12, 557-563. https://doi.org/10.1002/ana.410120610

Alexander, A.L., Lee, J.E., Lazar, M., Field, A.S., 2007. Diffusion tensor imaging of the brain. Neurotherapeutics 4, 316-329. https://doi.org/10.1016/j.nurt.2007.05.011

Alexander, D.C., Hubbard, P.L., Hall, M.G., Moore, E.A., Ptito, M., Parker, G.J.M., Dyrby, T.B., 2010. Orientationally invariant indices of axon diameter and density from diffusion MRI. Neuroimage 52, 1374-1389. https://doi.org/10.1016/j.neuroimage.2010.05.043

Andersson, J.L.R., Graham, M.S., Drobnjak, I., Zhang, H., Campbell, J., 2018. Susceptibility-induced distortion that varies due to motion: Correction in diffusion MR without acquiring additional data. Neuroimage 171, 277-295. https://doi.org/10.1016/j.neuroimage.2017.12.040

Andersson, J.L.R., Graham, M.S., Drobnjak, I., Zhang, H., Filippini, N., Bastiani, M., 2017. Towards a comprehensive framework for movement and distortion correction of diffusion MR images: Within volume movement. Neuroimage 152, 450-466. https://doi.org/10.1016/j.neuroimage.2017.02.085

Andersson, J.L.R., Graham, M.S., Zsoldos, E., Sotiropoulos, S.N., 2016. Incorporating outlier detection and replacement into a non-parametric framework for movement and distortion correction of diffusion MR images. Neuroimage 141, 556-572. https://doi.org/10.1016/j.neuroimage.2016.06.058

Andersson, J.L.R., Skare, S., Ashburner, J., 2003. How to correct susceptibility distortions in spin-echo echo-planar images: application to diffusion tensor imaging. Neuroimage 20, 870-888. https://doi.org/10.1016/S1053-8119(03)00336-7

Andersson, J.L.R., Sotiropoulos, S.N., 2016. An integrated approach to correction for off-resonance effects and subject movement in diffusion MR imaging. Neuroimage 125, 1063-1078. https://doi.org/10.1016/j.neuroimage.2015.10.019

Armstrong, R.C., Mierzwa, A.J., Marion, C.M., Sullivan, G.M., 2016. White matter involvement after TBI: Clues to axon and myelin repair capacity. Exp. Neurol. 275 Pt 3, 328-333. https://doi.org/10.1016/j.expneurol.2015.02.011

Avesani, P., McPherson, B., Hayashi, S., Caiafa, C.F., Henschel, R., Garyfallidis, E., Kitchell, L., Bullock, D., Patterson, A., Olivetti, E., Sporns, O., Saykin, A.J., Wang, L., Dinov, I., Hancock, D., Caron, B., Qian, Y., Pestilli, F., 2019. The open diffusion data derivatives, brain data upcycling via integrated publishing of derivatives and reproducible open cloud services. Scientific Data 6, 69. https://doi.org/10.1038/s41597-019-0073-y

Bahrami, N., Sharma, D., Rosenthal, S., Davenport, E.M., Urban, J.E., Wagner, B., Jung, Y., Vaughan, C.G., Gioia, G.A., Stitzel, J.D., Whitlow, C.T., Maldjian, J.A., 2016. Subconcussive Head Impact Exposure and White Matter Tract Changes over a Single Season of Youth Football. Radiology 281, 919. https://doi.org/10.1148/radiol.2016160564

Basser, P.J., Jones, D.K., 2002. Diffusion-tensor MRI: theory, experimental design and data analysis - a technical review. NMR Biomed. 15, 456-467. https://doi.org/10.1002/nbm.783

Basser, P.J., Mattiello, J., LeBihan, D., 1994a. MR diffusion tensor spectroscopy and imaging. Biophys. J. 66, 259-267. https://doi.org/10.1016/S0006-3495(94)80775-1

Basser, P.J., Mattiello, J., LeBihan, D., 1994b. Estimation of the effective self-diffusion tensor from the NMR spin echo. J. Magn. Reson. B 103, 247-254. https://doi.org/10.1006/jmrb.1994.1037

Bazarian, J.J., Zhu, T., Zhong, J., Janigro, D., Rozen, E., Roberts, A., Javien, H., Merchant-Borna, K., Abar, B., Blackman, E.G., 2014. Persistent, long-term cerebral white matter changes after sports-related repetitive head impacts. PLoS One 9, e94734. https://doi.org/10.1371/journal.pone.0094734

Bracht, T., Jones, D.K., Bells, S., Walther, S., Drakesmith, M., Linden, D., 2016. Myelination of the right parahippocampal cingulum is associated with physical activity in young healthy adults. Brain Struct. Funct. 221, 4537-4548. https://doi.org/10.1007/s00429-016-1183-3

Broglio, S.P., Schnebel, B., Sosnoff, J.J., Shin, S., Fend, X., He, X., Zimmerman, J., 2010. Biomechanical properties of concussions in high school football. Med. Sci. Sports Exerc. 42, 2064-2071. https://doi.org/10.1249/MSS.0b013e3181dd9156

Brunetta, H.S., Holwerda, A.M., van Loon, L.J.C., Holloway, G.P., 2020. Mitochondrial ROS and Aging: 
Understanding Exercise as a Preventive Tool. Journal of Science in Sport and Exercise 2, 15-24. https://doi.org/10.1007/s42978-019-00037-1

Bullock, D., Takemura, H., Caiafa, C.F., Kitchell, L., McPherson, B., Caron, B., Pestilli, F., 2019. Associative white matter connecting the dorsal and ventral posterior human cortex. Brain Struct. Funct. https://doi.org/10.1007/s00429-019-01907-8

Burzynska, A.Z., Wong, C.N., Chaddock-Heyman, L., Olson, E.A., Gothe, N.P., Knecht, A., Voss, M.W., McAuley, E., Kramer, A.F., 2016. White matter integrity, hippocampal volume, and cognitive performance of a world-famous nonagenarian track-and-field athlete. Neurocase 22, 135-144. https://doi.org/10.1080/13554794.2015.1074709

By, S., Xu, J., Box, B.A., Bagnato, F.R., Smith, S.A., 2017. Application and evaluation of NODDI in the cervical spinal cord of multiple sclerosis patients. Neuroimage Clin 15, 333-342. https://doi.org/10.1016/j.nicl.2017.05.010

Chaddock-Heyman, L., Erickson, K.I., Holtrop, J.L., Voss, M.W., Pontifex, M.B., Raine, L.B., Hillman, C.H., Kramer, A.F., 2014. Aerobic fitness is associated with greater white matter integrity in children. Front. Hum. Neurosci. 8, 584. https://doi.org/10.3389/fnhum.2014.00584

Chaddock-Heyman, L., Erickson, K.I., Kienzler, C., Drollette, E.S., Raine, L.B., Kao, S.-C., Bensken, J., Weisshappel, R., Castelli, D.M., Hillman, C.H., Kramer, A.F., 2018. Physical Activity Increases White Matter Microstructure in Children. Front. Neurosci. 12, 950. https://doi.org/10.3389/fnins.2018.00950

Chang, Y.-K., Tsai, J.H.-C., Wang, C.-C., Chang, E.C., 2015. Structural differences in basal ganglia of elite running versus martial arts athletes: a diffusion tensor imaging study. Exp. Brain Res. 233, 2239-2248. https://doi.org/10.1007/s00221-015-4293-x

Chappell, M.H., Uluğ, A.M., Zhang, L., Heitger, M.H., Jordan, B.D., Zimmerman, R.D., Watts, R., 2006. Distribution of microstructural damage in the brains of professional boxers: a diffusion MRI study. J. Magn. Reson. Imaging 24, 537-542. https://doi.org/10.1002/jmri.20656

Chayer, C., Freedman, M., 2001. Frontal lobe functions. Curr. Neurol. Neurosci. Rep. 1, 547-552.

Chun, I.Y., Mao, X., Breedlove, E.L., Leverenz, L.J., Nauman, E.A., Talavage, T.M., 2015. DTI Detection of Longitudinal WM Abnormalities Due to Accumulated Head Impacts. Dev. Neuropsychol. 40, 92-97. https://doi.org/10.1080/87565641.2015.1020945

Churchill, N.W., Caverzasi, E., Graham, S.J., Hutchison, M.G., Schweizer, T.A., 2018. White matter during concussion recovery: Comparing diffusion tensor imaging (DTI) and neurite orientation dispersion and density imaging (NODDI). Hum. Brain Mapp. https://doi.org/10.1002/hbm.24500

Churchill, N.W., Caverzasi, E., Graham, S.J., Hutchison, M.G., Schweizer, T.A., 2017a. White matter microstructure in athletes with a history of concussion: Comparing diffusion tensor imaging (DTI) and neurite orientation dispersion and density imaging (NODDI). Hum. Brain Mapp. 38, 4201-4211. https://doi.org/10.1002/hbm.23658

Churchill, N.W., Hutchison, M.G., Di Battista, A.P., Graham, S.J., Schweizer, T.A., 2017b. Structural, Functional, and Metabolic Brain Markers Differentiate Collision versus Contact and Non-Contact Athletes. Front. Neurol. 8, 390. https://doi.org/10.3389/fneur.2017.00390

Colgan, N., Siow, B., O'Callaghan, J.M., Harrison, I.F., Wells, J.A., Holmes, H.E., Ismail, O., Richardson, S., Alexander, D.C., Collins, E.C., Fisher, E.M., Johnson, R., Schwarz, A.J., Ahmed, Z., O'Neill, M.J., Murray, T.K., Zhang, H., Lythgoe, M.F., 2016. Application of neurite orientation dispersion and density imaging (NODDI) to a tau pathology model of Alzheimer's disease. Neuroimage 125, 739-744. https://doi.org/10.1016/j.neuroimage.2015.10.043

Crisco, J.J., Fiore, R., Beckwith, J.G., Chu, J.J., Brolinson, P.G., Duma, S., McAllister, T.W., Duhaime, A.-C., Greenwald, R.M., 2010. Frequency and location of head impact exposures in individual collegiate football players. J. Athl. Train. 45, 549-559. https://doi.org/10.4085/1062-6050-45.6.549

Crisco, J.J., Wilcox, B.J., Beckwith, J.G., Chu, J.J., Duhaime, A.-C., Rowson, S., Duma, S.M., Maerlender, A.C., McAllister, T.W., Greenwald, R.M., 2011. Head impact exposure in collegiate football players. J. Biomech. 44, 2673-2678. https://doi.org/10.1016/j.jbiomech.2011.08.003

Critchley, M., 1957. Medical aspects of boxing, particularly from a neurological standpoint. Br. Med. J. 1, 357-362.

Daducci, A., Canales-Rodríguez, E.J., Zhang, H., Dyrby, T.B., Alexander, D.C., Thiran, J.-P., 2015. Accelerated Microstructure Imaging via Convex Optimization (AMICO) from diffusion MRI data. Neuroimage 105, 32-44. https://doi.org/10.1016/j.neuroimage.2014.10.026

Dale, A., Fischl, B., Sereno, M.I., 1999. Cortical Surface-Based Analysis: I. Segmentation and Surface Reconstruction. Neuroimage 9, 179-194.

Dale, A.M., Sereno, M.I., 1993. Improved Localizadon of Cortical Activity by Combining EEG and MEG with MRI Cortical Surface Reconstruction: A Linear Approach. Journal of Cognitive Neuroscience. 
https://doi.org/10.1162/jocn.1993.5.2.162

Davenport, E.M., Apkarian, K., Whitlow, C.T., Urban, J.E., Jensen, J.H., Szuch, E., Espeland, M.A., Jung, Y., Rosenbaum, D.A., Gioia, G.A., Powers, A.K., Stitzel, J.D., Maldjian, J.A., 2016a. Abnormalities in Diffusional Kurtosis Metrics Related to Head Impact Exposure in a Season of High School Varsity Football. J. Neurotrauma 33, 2133-2146. https://doi.org/10.1089/neu.2015.4267

Davenport, E.M., Urban, J.E., Mokhtari, F., Lowther, E.L., Van Horn, J.D., Vaughan, C.G., Gioia, G.A., Whitlow, C.T., Stitzel, J.D., Maldjian, J.A., 2016b. Subconcussive impacts and imaging findings over a season of contact sports. Concussion 1, CNC19. https://doi.org/10.2217/cnc-2016-0003

Davenport, E.M., Whitlow, C.T., Urban, J.E., Espeland, M.A., Jung, Y., Rosenbaum, D.A., Gioia, G.A., Powers, A.K., Stitzel, J.D., Maldjian, J.A., 2014. Abnormal white matter integrity related to head impact exposure in a season of high school varsity football. J. Neurotrauma 31, 1617-1624. https://doi.org/10.1089/neu.2013.3233

Deng, F., Zhao, L., Liu, C., Lu, M., Zhang, S., Huang, H., Chen, L., Wu, X., Niu, C., He, Y., Wang, J., Huang, R., 2018. Plasticity in deep and superficial white matter: a DTI study in world class gymnasts. Brain Struct. Funct. 223, 1849-1862. https://doi.org/10.1007/s00429-017-1594-9

Descoteaux, M., Deriche, R., Le Bihan, D., Mangin, J.-F., Poupon, C., 2011. Multiple q-shell diffusion propagator imaging. Med. Image Anal. 15, 603-621. https://doi.org/10.1016/j.media.2010.07.001

Desikan, R.S., Ségonne, F., Fischl, B., Quinn, B.T., Dickerson, B.C., Blacker, D., Buckner, R.L., Dale, A.M., Maguire, R.P., Hyman, B.T., Albert, M.S., Killiany, R.J., 2006. An automated labeling system for subdividing the human cerebral cortex on MRI scans into gyral based regions of interest. Neuroimage 31, 968-980. https://doi.org/10.1016/j.neuroimage.2006.01.021

Destrieux, C., Fischl, B., Dale, A., Halgren, E., 2010. Automatic parcellation of human cortical gyri and sulci using standard anatomical nomenclature. Neuroimage 53, 1-15. https://doi.org/10.1016/j.neuroimage.2010.06.010

Duru, A.D., Balcioglu, T.H., 2018. Functional and Structural Plasticity of Brain in Elite Karate Athletes. J. Healthc. Eng. 2018, 8310975. https://doi.org/10.1155/2018/8310975

Ebbesen, C.L., Brecht, M., 2017. Motor cortex - to act or not to act? Nat. Rev. Neurosci. 18, 694-705. https://doi.org/10.1038/nrn.2017.119

El-Sayes, J., Harasym, D., Turco, C.V., Locke, M.B., Nelson, A.J., 2019. Exercise-Induced Neuroplasticity: A Mechanistic Model and Prospects for Promoting Plasticity. Neuroscientist 25, 65-85. https://doi.org/10.1177/1073858418771538

Errea, O., Moreno, B., Gonzalez-Franquesa, A., Garcia-Roves, P.M., Villoslada, P., 2015. The disruption of mitochondrial axonal transport is an early event in neuroinflammation. J. Neuroinflammation 12, 152. https://doi.org/10.1186/s12974-015-0375-8

Esteban-Cornejo, I., Rodriguez-Ayllon, M., Verdejo-Roman, J., Cadenas-Sanchez, C., Mora-Gonzalez, J., Chaddock-Heyman, L., Raine, L.B., Stillman, C.M., Kramer, A.F., Erickson, K.I., Catena, A., Ortega, F.B., Hillman, C.H., 2019. Physical Fitness, White Matter Volume and Academic Performance in Children: Findings From the ActiveBrains and FITKids2 Projects. Front. Psychol. 10, 208. https://doi.org/10.3389/fpsyg.2019.00208

Fick, R.H.J., Daianu, M., Pizzolato, M., Wassermann, D., Jacobs, R.E., Thompson, P.M., Town, T., Deriche, R., 2017. Comparison of Biomarkers in Transgenic Alzheimer Rats Using Multi-Shell Diffusion MRI, in: Computational Diffusion MRI. Springer International Publishing, pp. 187-199. https://doi.org/10.1007/978-3-319-54130-3_16

Fischl, B., 2012. FreeSurfer. Neuroimage 62, 774-781. https://doi.org/10.1016/j.neuroimage.2012.01.021

Fischl, B., Dale, A.M., 2000. Measuring the thickness of the human cerebral cortex from magnetic resonance images. Proc. Natl. Acad. Sci. U. S. A. 97, 11050-11055.

Fischl, B., Liu, A., Dale, A.M., 2001. Automated manifold surgery: constructing geometrically accurate and topologically correct models of the human cerebral cortex. IEEE Medical Imaging 20, 70-80.

Fischl, B., Salat, D.H., Busa, E., Albert, M., Dieterich, M., Haselgrove, C., van der Kouwe, A., Killiany, R., Kennedy, D., Klaveness, S., Montillo, A., Makris, N., Rosen, B., Dale, A.M., 2002. Whole brain segmentation: automated labeling of neuroanatomical structures in the human brain. Neuron 33, 341-355. https://doi.org/10.1016/s0896-6273(02)00569-x

Fischl, B., Salat, D.H., Busa, E., Albert, M., Dieterich, M., Haselgrove, C., van der Kouwe, A., Killiany, R., Kennedy, D., Klaveness, S., Montillo, A., Makris, N., Rosen, B., Dale, A.M., 2002. Whole brain segmentation: automated labeling of neuroanatomical structures in the human brain. Neuron 33, 341-355.

Fischl, B., Salat, D.H., van der Kouwe, A.J.W., Makris, N., Ségonne, F., Quinn, B.T., Dale, A.M., 2004a. Sequence-independent segmentation of magnetic resonance images. Neuroimage 23, S69-S84. https://doi.org/10.1016/j.neuroimage.2004.07.016

Fischl, B., Sereno, M.I., Dale, A., 1999a. Cortical Surface-Based Analysis: II: Inflation, Flattening, and a 
Surface-Based Coordinate System. Neuroimage 9, 195-207.

Fischl, B., Sereno, M.I., Tootell, R.B.H., Dale, A.M., 1999b. High-resolution intersubject averaging and a coordinate system for the cortical surface. Hum. Brain Mapp. 8, 272-284.

https://doi.org/3.0.CO;2-4">10.1002/(SICI)1097-0193(1999)8:4<272::AID-HBM10>3.0.CO;2-4

Fischl, B., van der Kouwe, A., Destrieux, C., Halgren, E., Ségonne, F., Salat, D.H., Busa, E., Seidman, L.J., Goldstein, J., Kennedy, D., Caviness, V., Makris, N., Rosen, B., Dale, A.M., 2004b. Automatically Parcellating the Human Cerebral Cortex. Cereb. Cortex 14, 11-22. https://doi.org/10.1093/cercor/bhg087

Frank, L.R., 2002. Characterization of anisotropy in high angular resolution diffusion-weighted MRI. Magn. Reson. Med. 47, 1083-1099. https://doi.org/10.1002/mrm.10156

Frati, A., Cerretani, D., Fiaschi, A.I., Frati, P., Gatto, V., La Russa, R., Pesce, A., Pinchi, E., Santurro, A., Fraschetti, F., Fineschi, V., 2017. Diffuse Axonal Injury and Oxidative Stress: A Comprehensive Review. Int. J. Mol. Sci. 18. https://doi.org/10.3390/ijms 18122600

Fukutomi, H., Glasser, M.F., Murata, K., Akasaka, T., Fujimoto, K., Yamamoto, T., Autio, J.A., Okada, T., Togashi, K., Zhang, H., Van Essen, D.C., Hayashi, T., 2019. Diffusion Tensor Model links to Neurite Orientation Dispersion and Density Imaging at high b-value in Cerebral Cortical Gray Matter. Sci. Rep. 9, 12246. https://doi.org/10.1038/s41598-019-48671-7

Fukutomi, H., Glasser, M.F., Zhang, H., Autio, J.A., Coalson, T.S., Okada, T., Togashi, K., Van Essen, D.C., Hayashi, T., 2018. Neurite imaging reveals microstructural variations in human cerebral cortical gray matter. Neuroimage. https://doi.org/10.1016/j.neuroimage.2018.02.017

Gaetz, M., 2004. The neurophysiology of brain injury. Clin. Neurophysiol. 115, 4-18. https://doi.org/10.1016/S1388-2457(03)00258-X

Gajawelli, N., Lao, Y., Apuzzo, M.L.J., Romano, R., Liu, C., Tsao, S., Hwang, D., Wilkins, B., Lepore, N., Law, M., 2013. Neuroimaging changes in the brain in contact versus noncontact sport athletes using diffusion tensor imaging. World Neurosurg. 80, 824-828. https://doi.org/10.1016/j.wneu.2013.10.020

Garyfallidis, E., Brett, M., Amirbekian, B., Rokem, A., van der Walt, S., Descoteaux, M., Nimmo-Smith, I., Dipy Contributors, 2014. Dipy, a library for the analysis of diffusion MRI data. Front. Neuroinform. 8, 8. https://doi.org/10.3389/fninf.2014.00008

Gavett, B.E., Stern, R.A., McKee, A.C., 2011. Chronic traumatic encephalopathy: a potential late effect of sport-related concussive and subconcussive head trauma. Clin. Sports Med. 30, 179-88, xi. https://doi.org/10.1016/j.csm.2010.09.007

Geddes, D.M., Cargill, R.S., 2nd, LaPlaca, M.C., 2003a. Mechanical stretch to neurons results in a strain rate and magnitude-dependent increase in plasma membrane permeability. J. Neurotrauma 20, 1039-1049. https://doi.org/10.1089/089771503770195885

Geddes, D.M., LaPlaca, M.C., Cargill, R.S., 2nd, 2003b. Susceptibility of hippocampal neurons to mechanically induced injury. Exp. Neurol. 184, 420-427.

Gennarelli, T.A., Thibault, L.E., Adams, J.H., Graham, D.I., Thompson, C.J., Marcincin, R.P., 1982. Diffuse axonal injury and traumatic coma in the primate. Ann. Neurol. 12, 564-574. https://doi.org/10.1002/ana.410120611

Gerard, R.W., Marshall, W.H., Saul, L.J., 1933. Cerebral Action Potentials. Proc. Soc. Exp. Biol. Med. 30, 1123-1125. https://doi.org/10.3181/00379727-30-6817

Giza, C.C., Hovda, D.A., 2014. The new neurometabolic cascade of concussion. Neurosurgery 75 Suppl 4, S24-33. https://doi.org/10.1227/NEU.0000000000000505

Gleeson, M., 2007. Immune function in sport and exercise. J. Appl. Physiol. 103, 693-699. https://doi.org/10.1152/japplphysiol.00008.2007

Gogolla, N., 2017. The insular cortex. Curr. Biol. 27, R580-R586. https://doi.org/10.1016/j.cub.2017.05.010

Gong, N.-J., Kuzminski, S., Clark, M., Fraser, M., Sundman, M., Guskiewicz, K., Petrella, J.R., Liu, C., 2018. Microstructural alterations of cortical and deep gray matter over a season of high school football revealed by diffusion kurtosis imaging. Neurobiol. Dis. 119, 79-87. https://doi.org/10.1016/j.nbd.2018.07.020

Graham, R., Rivara, F.P., Ford, M.A., Spicer, C.M., Committee on Sports-Related Concussions in Youth, Board on Children, Youth, and Families, Institute of Medicine, National Research Council, 2014. Consequences of Repetitive Head Impacts and Multiple Concussions. National Academies Press (US).

Greve, D.N., Fischl, B., 2009. Accurate and robust brain image alignment using boundary-based registration. Neuroimage 48, 63-72. https://doi.org/10.1016/j.neuroimage.2009.06.060

Gunstad, J., Paul, R.H., Cohen, R.A., Tate, D.F., Spitznagel, M.B., Grieve, S., Gordon, E., 2008. Relationship between body mass index and brain volume in healthy adults. Int. J. Neurosci. 118, 1582-1593. https://doi.org/10.1080/00207450701392282

Gysland, S.M., Mihalik, J.P., Register-Mihalik, J.K., Trulock, S.C., Shields, E.W., Guskiewicz, K.M., 2012. The relationship between subconcussive impacts and concussion history on clinical measures of neurologic 
function in collegiate football players. Ann. Biomed. Eng. 40, 14-22.

https://doi.org/10.1007/s10439-011-0421-3

Hadžović-Džuvo, A., Valjevac, A., Lepara, O., Pjanić, S., Hadžimuratović, A., Mekić, A., 2014. Oxidative stress status in elite athletes engaged in different sport disciplines. Bosn. J. Basic Med. Sci. 14, 56-62. https://doi.org/10.17305/bjbms.2014.2262

Hänggi, J., Koeneke, S., Bezzola, L., Jäncke, L., 2010. Structural neuroplasticity in the sensorimotor network of professional female ballet dancers. Hum. Brain Mapp. 31, 1196-1206. https://doi.org/10.1002/hbm.20928

Hänggi, J., Langer, N., Lutz, K., Birrer, K., Mérillat, S., Jäncke, L., 2015. Structural brain correlates associated with professional handball playing. PLoS One 10, e0124222. https://doi.org/10.1371/journal.pone.0124222

Han, X., Jovicich, J., Salat, D., van der Kouwe, A., Quinn, B., Czanner, S., Busa, E., Pacheco, J., Albert, M., Killiany, R., Maguire, P., Rosas, D., Makris, N., Dale, A., Dickerson, B., Fischl, B., 2006. Reliability of MRI-derived measurements of human cerebral cortical thickness: The effects of field strength, scanner upgrade and manufacturer. Neuroimage 32, 180-194.

Hayes, S.M., Salat, D.H., Forman, D.E., Sperling, R.A., Verfaellie, M., 2015. Cardiorespiratory fitness is associated with white matter integrity in aging. Ann Clin Transl Neurol 2, 688-698. https://doi.org/10.1002/acn3.204

Hillman, C.H., Erickson, K.I., Kramer, A.F., 2008. Be smart, exercise your heart: exercise effects on brain and cognition. Nat. Rev. Neurosci. 9, 58-65. https://doi.org/10.1038/nrn2298

Hootman, J.M., Dick, R., Agel, J., 2007. Epidemiology of collegiate injuries for 15 sports: summary and recommendations for injury prevention initiatives. J. Athl. Train. 42, 311-319.

Hötting, K., Röder, B., 2013. Beneficial effects of physical exercise on neuroplasticity and cognition. Neurosci. Biobehav. Rev. 37, 2243-2257. https://doi.org/10.1016/j.neubiorev.2013.04.005

Huang, C., Irwin, M.G., Wong, G.T.C., Chang, R.C.C., 2018. Evidence of the impact of systemic inflammation on neuroinflammation from a non-bacterial endotoxin animal model. J. Neuroinflammation 15, 147. https://doi.org/10.1186/s12974-018-1163-z

Irimia, A., Chambers, M.C., Torgerson, C.M., Van Horn, J.D., 2012. Circular representation of human cortical networks for subject and population-level connectomic visualization. Neuroimage 60, 1340-1351. https://doi.org/10.1016/j.neuroimage.2012.01.107

Israelsson, C., Bengtsson, H., Kylberg, A., Kullander, K., Lewén, A., Hillered, L., Ebendal, T., 2008. Distinct cellular patterns of upregulated chemokine expression supporting a prominent inflammatory role in traumatic brain injury. J. Neurotrauma 25, 959-974. https://doi.org/10.1089/neu.2008.0562

Jäncke, L., Koeneke, S., Hoppe, A., Rominger, C., Hänggi, J., 2009. The architecture of the golfer's brain. PLoS One 4, e4785. https://doi.org/10.1371/journal.pone.0004785

Jelescu, I.O., Budde, M.D., 2017. Design and validation of diffusion MRI models of white matter. Front. Phys. 28. https://doi.org/10.3389/fphy.2017.00061

Jenkinson, M., Bannister, P., Brady, M., Smith, S., 2002. Improved optimization for the robust and accurate linear registration and motion correction of brain images. Neuroimage 17, 825-841. https://doi.org/10.1016/s1053-8119(02)91132-8

Jenkinson, M., Beckmann, C.F., Behrens, T.E.J., Woolrich, M.W., Smith, S.M., 2012. FSL. Neuroimage 62, 782-790. https://doi.org/10.1016/j.neuroimage.2011.09.015

Jenkinson, M., Smith, S., 2001. A global optimisation method for robust affine registration of brain images. Med. Image Anal. 5, 143-156. https://doi.org/10.1016/s1361-8415(01)00036-6

Jeurissen, B., Leemans, A., Sijbers, J., 2014a. Automated correction of improperly rotated diffusion gradient orientations in diffusion weighted MRI. Med. Image Anal. 18, 953-962. https://doi.org/10.1016/j.media.2014.05.012

Jeurissen, B., Leemans, A., Tournier, J.-D., Jones, D.K., Sijbers, J., 2013. Investigating the prevalence of complex fiber configurations in white matter tissue with diffusion magnetic resonance imaging. Hum. Brain Mapp. 34, 2747-2766. https://doi.org/10.1002/hbm.22099

Jeurissen, B., Tournier, J.-D., Dhollander, T., Connelly, A., Sijbers, J., 2014b. Multi-tissue constrained spherical deconvolution for improved analysis of multi-shell diffusion MRI data. Neuroimage 103, 411-426. https://doi.org/10.1016/j.neuroimage.2014.07.061

Johnson, V.E., Stewart, W., Smith, D.H., 2013. Axonal pathology in traumatic brain injury. Exp. Neurol. 246, 35-43. https://doi.org/10.1016/j.expneurol.2012.01.013

Jones, D.K., Knösche, T.R., Turner, R., 2013. White matter integrity, fiber count, and other fallacies: the do's and don'ts of diffusion MRI. Neuroimage 73, 239-254. https://doi.org/10.1016/j.neuroimage.2012.06.081

Jovicich, J., Czanner, S., Greve, D., Haley, E., van der Kouwe, A., Gollub, R., Kennedy, D., Schmitt, F., Brown, G., MacFall, J., Fischl, B., Dale, A., 2006. Reliability in multi-site structural MRI studies: Effects of gradient non-linearity correction on phantom and human data. Neuroimage 30, 436-443. 
https://doi.org/10.1016/j.neuroimage.2005.09.046

Kaden, E., Kelm, N.D., Carson, R.P., Does, M.D., Alexander, D.C., 2016. Multi-compartment microscopic diffusion imaging. Neuroimage 139, 346-359. https://doi.org/10.1016/j.neuroimage.2016.06.002

Kanwisher, N., 2010. Functional specificity in the human brain: a window into the functional architecture of the mind. Proc. Natl. Acad. Sci. U. S. A. 107, 11163-11170. https://doi.org/10.1073/pnas.1005062107

Kao, C.-Q., Goforth, P.B., Ellis, E.F., Satin, L.S., 2004. Potentiation of GABA(A) currents after mechanical injury of cortical neurons. J. Neurotrauma 21, 259-270. https://doi.org/10.1089/089771504322972059

Kempuraj, D., Thangavel, R., Selvakumar, G.P., Zaheer, S., Ahmed, M.E., Raikwar, S.P., Zahoor, H., Saeed, D., Natteru, P.A., lyer, S., Zaheer, A., 2017. Brain and Peripheral Atypical Inflammatory Mediators Potentiate Neuroinflammation and Neurodegeneration. Front. Cell. Neurosci. 11, 216. https://doi.org/10.3389/fncel.2017.00216

Kerr, Z.Y., Roos, K.G., Djoko, A., Dalton, S.L., Broglio, S.P., Marshall, S.W., Dompier, T.P., 2017. Epidemiologic Measures for Quantifying the Incidence of Concussion in National Collegiate Athletic Association Sports. J. Athl. Train. 52, 167-174. https://doi.org/10.4085/1062-6050-51.6.05

Kilinc, D., Gallo, G., Barbee, K.A., 2009. Mechanical membrane injury induces axonal beading through localized activation of calpain. Exp. Neurol. 219, 553-561. https://doi.org/10.1016/j.expneurol.2009.07.014

Kilinc, D., Gallo, G., Barbee, K.A., 2008. Mechanically-induced membrane poration causes axonal beading and localized cytoskeletal damage. Exp. Neurol. 212, 422-430. https://doi.org/10.1016/j.expneurol.2008.04.025

Koerte, I.K., Kaufmann, D., Hartl, E., Bouix, S., Pasternak, O., Kubicki, M., Rauscher, A., Li, D.K.B., Dadachanji, S.B., Taunton, J.A., Forwell, L.A., Johnson, A.M., Echlin, P.S., Shenton, M.E., 2012. A prospective study of physician-observed concussion during a varsity university hockey season: white matter integrity in ice hockey players. Part 3 of 4. Neurosurg. Focus 33, E3: 1-7. https://doi.org/10.3171/2012.10.FOCUS12303

Koerte, I.K., Lin, A.P., Willems, A., Muehlmann, M., Hufschmidt, J., Coleman, M.J., Green, I., Liao, H., Tate, D.F., Wilde, E.A., Pasternak, O., Bouix, S., Rathi, Y., Bigler, E.D., Stern, R.A., Shenton, M.E., 2015. A review of neuroimaging findings in repetitive brain trauma. Brain Pathol. 25, 318-349. https://doi.org/10.1111/bpa.12249

Kuperberg, G.R., Broome, M., McGuire, P.K., David, A.S., Eddy, M., Ozawa, F., Goff, D., West, W.C., Williams, S.C.R., van der Kouwe, A., Salat, D., Dale, A., Fischl, B., 2003. Regionally localized thinning of the cerebral cortex in Schizophrenia. Arch. Gen. Psychiatry 60, 878-888.

Kuzminski, S.J., Clark, M.D., Fraser, M.A., Haswell, C.C., Morey, R.A., Liu, C., Choudhury, K.R., Guskiewicz, K.M., Petrella, J.R., 2018. White Matter Changes Related to Subconcussive Impact Frequency during a Single Season of High School Football. AJNR Am. J. Neuroradiol. 39, 245-251. https://doi.org/10.3174/ajnr.A5489

Lamb, R.G., Harper, C.C., McKinney, J.S., Rzigalinski, B.A., Ellis, E.F., 1997. Alterations in phosphatidylcholine metabolism of stretch-injured cultured rat astrocytes. J. Neurochem. 68, 1904-1910.

Lampinen, B., Szczepankiewicz, F., Mårtensson, J., van Westen, D., Sundgren, P.C., Nilsson, M., 2017. Neurite density imaging versus imaging of microscopic anisotropy in diffusion MRI: A model comparison using spherical tensor encoding. Neuroimage 147, 517-531. https://doi.org/10.1016/j.neuroimage.2016.11.053

Lao, Y., Law, M., Shi, J., Gajawelli, N., Haas, L., Wang, Y., Leporé, N., 2015. A T1 and DTI fused 3D Corpus Callosum analysis in pre- vs. post-season contact sports players. Proc. SPIE Int. Soc. Opt. Eng. 9287. https://doi.org/10.1117/12.2072600

LaPlaca, M.C., Cullen, D.K., McLoughlin, J.J., Cargill, R.S., 2nd, 2005. High rate shear strain of three-dimensional neural cell cultures: a new in vitro traumatic brain injury model. J. Biomech. 38, 1093-1105. https://doi.org/10.1016/j.jbiomech.2004.05.032

Lee, H.-H., Papaioannou, A., Kim, S.-L., Novikov, D.S., Fieremans, E., 2020. A time-dependent diffusion MRI signature of axon caliber variations and beading. Commun Biol 3, 354. https://doi.org/10.1038/s42003-020-1050-x

Lefebvre, G., Guay, S., Chamard, E., Theaud, G., de Guise, E., Bacon, B., Descoteaux, M., De Beaumont, L., Théoret, H., 2020. Diffusion tensor imaging in contact and non-contact university-level sport athletes. J. Neurotrauma. https://doi.org/10.1089/neu.2020.7170

Luo, T., Oladosu, O., Rawji, K.S., Zhai, P., Pridham, G., Hossain, S., Zhang, Y., 2018. Characterizing Structural Changes With Devolving Remyelination Following Experimental Demyelination Using High Angular Resolution Diffusion MRI and Texture Analysis. J. Magn. Reson. Imaging. https://doi.org/10.1002/jmri.26328

Marchi, N., Bazarian, J.J., Puvenna, V., Janigro, M., Ghosh, C., Zhong, J., Zhu, T., Blackman, E., Stewart, D., Ellis, J., Butler, R., Janigro, D., 2013. Consequences of repeated blood-brain barrier disruption in football players. PLoS One 8, e56805. https://doi.org/10.1371/journal.pone.0056805

Maxwell, W.L., Bartlett, E., Morgan, H., 2015. Wallerian degeneration in the optic nerve stretch-injury model of traumatic brain injury: a stereological analysis. J. Neurotrauma 32, 780-790. 
https://doi.org/10.1089/neu.2014.3369

Maxwell, W.L., Graham, D.I., 1997. Loss of axonal microtubules and neurofilaments after stretch-injury to guinea pig optic nerve fibers. J. Neurotrauma 14, 603-614. https://doi.org/10.1089/neu.1997.14.603

Mayer, A.R., Ling, J.M., Dodd, A.B., Meier, T.B., Hanlon, F.M., Klimaj, S.D., 2017. A prospective microstructure imaging study in mixed-martial artists using geometric measures and diffusion tensor imaging: methods and findings. Brain Imaging Behav. 11, 698-711. https://doi.org/10.1007/s11682-016-9546-1

Mayinger, M.C., Merchant-Borna, K., Hufschmidt, J., Muehlmann, M., Weir, I.R., Rauchmann, B.-S., Shenton, M.E., Koerte, I.K., Bazarian, J.J., 2018. White matter alterations in college football players: a longitudinal diffusion tensor imaging study. Brain Imaging Behav. 12, 44-53. https://doi.org/10.1007/s11682-017-9672-4

McAllister, T.W., 2011. Neurobiological consequences of traumatic brain injury. Dialogues Clin. Neurosci. 13, 287-300.

McAllister, T.W., Ford, J.C., Flashman, L.A., Maerlender, A., Greenwald, R.M., Beckwith, J.G., Bolander, R.P., Tosteson, T.D., Turco, J.H., Raman, R., Jain, S., 2014. Effect of head impacts on diffusivity measures in a cohort of collegiate contact sport athletes. Neurology 82, 63-69. https://doi.org/10.1212/01.wnl.0000438220.16190.42

McKee, A.C., Cantu, R.C., Nowinski, C.J., Hedley-Whyte, E.T., Gavett, B.E., Budson, A.E., Santini, V.E., Lee, H.-S., Kubilus, C.A., Stern, R.A., 2009. Chronic traumatic encephalopathy in athletes: progressive tauopathy after repetitive head injury. J. Neuropathol. Exp. Neurol. 68, 709-735. https://doi.org/10.1097/NEN.0b013e3181a9d503

McKee, A.C., Stein, T.D., Kiernan, P.T., Alvarez, V.E., 2015. The neuropathology of chronic traumatic encephalopathy. Brain Pathol. 25, 350-364. https://doi.org/10.1111/bpa.12248

Meaney, D.F., Smith, D.H., 2011. Biomechanics of concussion. Clin. Sports Med. 30, 19-31, vii. https://doi.org/10.1016/j.csm.2010.08.009

Meier, T.B., Bellgowan, P.S.F., Bergamino, M., Ling, J.M., Mayer, A.R., 2016. Thinner Cortex in Collegiate Football Players With, but not Without, a Self-Reported History of Concussion. J. Neurotrauma 33, 330-338. https://doi.org/10.1089/neu.2015.3919

Merchant-Borna, K., Asselin, P., Narayan, D., Abar, B., Jones, C.M.C., Bazarian, J.J., 2016. Novel Method of Weighting Cumulative Helmet Impacts Improves Correlation with Brain White Matter Changes After One Football Season of Sub-concussive Head Blows. Ann. Biomed. Eng. 44, 3679-3692. https://doi.org/10.1007/s10439-016-1680-9

Mez, J., Daneshvar, D.H., Kiernan, P.T., Abdolmohammadi, B., Alvarez, V.E., Huber, B.R., Alosco, M.L., Solomon, T.M., Nowinski, C.J., McHale, L., Cormier, K.A., Kubilus, C.A., Martin, B.M., Murphy, L., Baugh, C.M., Montenigro, P.H., Chaisson, C.E., Tripodis, Y., Kowall, N.W., Weuve, J., McClean, M.D., Cantu, R.C., Goldstein, L.E., Katz, D.I., Stern, R.A., Stein, T.D., McKee, A.C., 2017. Clinicopathological Evaluation of Chronic Traumatic Encephalopathy in Players of American Football. JAMA 318, 360-370. https://doi.org/10.1001/jama.2017.8334

Mitchell, T., Archer, D.B., Chu, W.T., Coombes, S.A., Lai, S., Wilkes, B.J., McFarland, N.R., Okun, M.S., Black, M.L., Herschel, E., Simuni, T., Comella, C., Xie, T., Li, H., Parrish, T.B., Kurani, A.S., Corcos, D.M., Vaillancourt, D.E., 2019. Neurite orientation dispersion and density imaging (NODDI) and free-water imaging in Parkinsonism. Hum. Brain Mapp. 40, 5094-5107. https://doi.org/10.1002/hbm.24760

Montenigro, P.H., Alosco, M.L., Martin, B.M., Daneshvar, D.H., Mez, J., Chaisson, C.E., Nowinski, C.J., Au, R., McKee, A.C., Cantu, R.C., McClean, M.D., Stern, R.A., Tripodis, Y., 2017. Cumulative Head Impact Exposure Predicts Later-Life Depression, Apathy, Executive Dysfunction, and Cognitive Impairment in Former High School and College Football Players. J. Neurotrauma 34, 328-340. https://doi.org/10.1089/neu.2016.4413

Mori, S., Wakana, S., van Zijl, P.C.M., Nagae-Poetscher, L.M., 2005. MRI Atlas of Human White Matter. Elsevier. Myer, G.D., Barber Foss, K., Thomas, S., Galloway, R., DiCesare, C.A., Dudley, J., Gadd, B., Leach, J., Smith, D., Gubanich, P., Meehan, W.P., 3rd, Altaye, M., Lavin, P., Yuan, W., 2018. Altered brain microstructure in association with repetitive subconcussive head impacts and the potential protective effect of jugular vein compression: a longitudinal study of female soccer athletes. Br. J. Sports Med. https://doi.org/10.1136/bjsports-2018-099571

Myer, G.D., Yuan, W., Barber Foss, K.D., Smith, D., Altaye, M., Reches, A., Leach, J., Kiefer, A.W., Khoury, J.C., Weiss, M., Thomas, S., Dicesare, C., Adams, J., Gubanich, P.J., Geva, A., Clark, J.F., Meehan, W.P., 3rd, Mihalik, J.P., Krueger, D., 2016a. The Effects of External Jugular Compression Applied during Head Impact Exposure on Longitudinal Changes in Brain Neuroanatomical and Neurophysiological Biomarkers: A Preliminary Investigation. Front. Neurol. 7, 74. https://doi.org/10.3389/fneur.2016.00074

Myer, G.D., Yuan, W., Barber Foss, K.D., Thomas, S., Smith, D., Leach, J., Kiefer, A.W., Dicesare, C., Adams, J., Gubanich, P.J., Kitchen, K., Schneider, D.K., Braswell, D., Krueger, D., Altaye, M., 2016b. Analysis of head 
impact exposure and brain microstructure response in a season-long application of a jugular vein compression collar: a prospective, neuroimaging investigation in American football. Br. J. Sports Med. 50, 1276-1285. https://doi.org/10.1136/bjsports-2016-096134

Nevin, N.C., 1967. Neuropathological changes in the white matter following head injury. J. Neuropathol. Exp. Neurol. 26, 77-84. https://doi.org/10.1097/00005072-196701000-00006

Novikov, D.S., Reisert, M., Kiselev, V.G., 2018. Effects of mesoscopic susceptibility and transverse relaxation on diffusion NMR. Journal of Magnetic Resonance. https://doi.org/10.1016/j.jmr.2018.06.007

Park, I.S., Lee, Y.N., Kwon, S., Lee, N.J., Rhyu, I.J., 2015. White matter plasticity in the cerebellum of elite basketball athletes. Anat. Cell Biol. 48, 262-267. https://doi.org/10.5115/acb.2015.48.4.262

Pedregosa, F., Varoquaux, G., Gramfort, A., Michel, V., Thirion, B., Grisel, O., Blondel, M., Prettenhofer, P., Weiss, R., Dubourg, V., Vanderplas, J., Passos, A., Cournapeau, D., Brucher, M., Perrot, M., Duchesnay, É., 2011. Scikit-learn: Machine Learning in Python. J. Mach. Learn. Res. 12, 2825-2830.

Penedo, F.J., Dahn, J.R., 2005. Exercise and well-being: a review of mental and physical health benefits associated with physical activity. Curr. Opin. Psychiatry 18, 189-193. https://doi.org/10.1097/00001504-200503000-00013

Pestilli, F., 2018. Human white matter and knowledge representation. PLoS Biol. 16, e2005758. https://doi.org/10.1371/journal.pbio.2005758

Pestilli, F., Carrasco, M., Heeger, D.J., Gardner, J.L., 2011. Attentional enhancement via selection and pooling of early sensory responses in human visual cortex. Neuron 72, 832-846. https://doi.org/10.1016/j.neuron.2011.09.025

Pestilli, F., Yeatman, J.D., Rokem, A., Kay, K.N., Wandell, B.A., 2014. Evaluation and statistical inference for human connectomes. Nat. Methods 11, 1058-1063. https://doi.org/10.1038/nmeth.3098

Pettus, E.H., Christman, C.W., Giebel, M.L., Povlishock, J.T., 1994. Traumatically induced altered membrane permeability: its relationship to traumatically induced reactive axonal change. J. Neurotrauma 11, 507-522. https://doi.org/10.1089/neu.1994.11.507

Pierpaoli, C., Barnett, A., Pajevic, S., Chen, R., Penix, L.R., Virta, A., Basser, P., 2001. Water diffusion changes in Wallerian degeneration and their dependence on white matter architecture. Neuroimage 13, 1174-1185. https://doi.org/10.1006/nimg.2001.0765

Pierpaoli, C., Jezzard, P., Basser, P.J., Barnett, A., Di Chiro, G., 1996. Diffusion tensor MR imaging of the human brain. Radiology 201, 637-648. https://doi.org/10.1148/radiology.201.3.8939209

Povlishock, J.T., Becker, D.P., 1985. Fate of reactive axonal swellings induced by head injury. Lab. Invest. 52, 540-552.

Povlishock, J.T., Becker, D.P., Cheng, C.L., Vaughan, G.W., 1983. Axonal change in minor head injury. J. Neuropathol. Exp. Neurol. 42, 225-242. https://doi.org/10.1097/00005072-198305000-00002

Povlishock, J.T., Katz, D.I., 2005. Update of neuropathology and neurological recovery after traumatic brain injury. J. Head Trauma Rehabil. 20, 76-94.

Powers, S.K., Deminice, R., Ozdemir, M., Yoshihara, T., Bomkamp, M.P., Hyatt, H., 2020. Exercise-induced oxidative stress: Friend or foe? J Sport Health Sci. https://doi.org/10.1016/j.jshs.2020.04.001

Radak, Z., Marton, O., Nagy, E., Koltai, E., Goto, S., 2013. The complex role of physical exercise and reactive oxygen species on brain. Journal of Sport and Health Science 2, 87-93. https://doi.org/10.1016/j.jshs.2013.04.001

Rajmohan, V., Mohandas, E., 2007. The limbic system. Indian J. Psychiatry 49, 132-139. https://doi.org/10.4103/0019-5545.33264

Reimers, C.D., Knapp, G., Reimers, A.K., 2012. Does physical activity increase life expectancy? A review of the literature. J. Aging Res. 2012, 243958. https://doi.org/10.1155/2012/243958

Reuter, M., Fischl, B., 2011. Avoiding Asymmetry-Induced Bias in Longitudinal Image Processing. Neuroimage 57, 19-21. https://doi.org/10.1016/j.neuroimage.2011.02.076

Reuter, M., Rosas, H.D., Fischl, B., 2010. Highly Accurate Inverse Consistent Registration: A Robust Approach. Neuroimage 53, 1181-1196. https://doi.org/10.1016/j.neuroimage.2010.07.020

Reuter, M., Schmansky, N.J., Rosas, H.D., Fischl, B., 2012. Within-subject template estimation for unbiased longitudinal image analysis. Neuroimage 61, 1402-1418. https://doi.org/10.1016/j.neuroimage.2012.02.084

Rice, S.M., Gwyther, K., Santesteban-Echarri, O., Baron, D., Gorczynski, P., Gouttebarge, V., Reardon, C.L., Hitchcock, M.E., Hainline, B., Purcell, R., 2019. Determinants of anxiety in elite athletes: a systematic review and meta-analysis. Br. J. Sports Med. 53, 722-730. https://doi.org/10.1136/bjsports-2019-100620

Roberts, A.H., 1969. Brain damage in boxers: a study of the prevalence of traumatic encephalopathy among ex-professional boxers. Pitman Medical \& Scientific Publishing Co., Ltd.

Rokem, A., Takemura, H., Bock, A.S., Scherf, K.S., Behrmann, M., Wandell, B.A., Fine, I., Bridge, H., Pestilli, F., 
2017. The visual white matter: The application of diffusion MRI and fiber tractography to vision scienceRokem et al. J. Vis. 17, 4-4.

Rosas, H.D., Liu, A.K., Hersch, S., Glessner, M., Ferrante, R.J., Salat, D.H., van der Kouwe, A., Jenkins, B.G., Dale, A.M., Fischl, B., 2002. Regional and progressive thinning of the cortical ribbon in Huntington's disease. Neurology 58, 695-701. https://doi.org/10.1212/wnl.58.5.695

Rotshenker, S., 2007. Wallerian Degeneration, in: Schmidt, R.F., Willis, W.D. (Eds.), Encyclopedia of Pain. Springer Berlin Heidelberg, Berlin, Heidelberg, pp. 2659-2662. https://doi.org/10.1007/978-3-540-29805-2_4855

Rubin, T.G., Catenaccio, E., Fleysher, R., Hunter, L.E., Lubin, N., Stewart, W.F., Kim, M., Lipton, R.B., Lipton, M.L., 2018. MRI-defined White Matter Microstructural Alteration Associated with Soccer Heading Is More Extensive in Women than Men. Radiology 289, 478-486. https://doi.org/10.1148/radiol.2018180217

Ruotsalainen, I., Gorbach, T., Perkola, J., Renvall, V., Syväoja, H.J., Tammelin, T.H., Karvanen, J., Parviainen, T., 2020. Physical activity, aerobic fitness, and brain white matter: Their role for executive functions in adolescence. Dev. Cogn. Neurosci. 42, 100765. https://doi.org/10.1016/j.dcn.2020.100765

Saghafi, B., Murugesan, G., Davenport, E., Wagner, B., Urban, J., Kelley, M., Jones, D., Powers, A., Whitlow, C., Stitzel, J., Maldjian, J., Montillo, A., 2018. Quantifying the association between white matter integrity changes and subconcussive head impact exposure from a single season of youth and high school football using 3D convolutional neural networks, in: Medical Imaging 2018: Computer-Aided Diagnosis. Presented at the Medical Imaging 2018: Computer-Aided Diagnosis, International Society for Optics and Photonics, p. 105750E. https://doi.org/10.1117/12.2293023

Salat, D., Buckner, R.L., Snyder, A.Z., Greve, D.N., Desikan, R.S., Busa, E., Morris, J.C., Dale, A., Fischl, B., 2004. Thinning of the cerebral cortex in aging. Cereb. Cortex 14, 721-730.

Saraulli, D., Costanzi, M., Mastrorilli, V., Farioli-Vecchioli, S., 2017. The Long Run: Neuroprotective Effects of Physical Exercise on Adult Neurogenesis from Youth to Old Age. Curr. Neuropharmacol. 15, 519-533. https://doi.org/10.2174/1570159X14666160412150223

Sato, K., Kerever, A., Kamagata, K., Tsuruta, K., Irie, R., Tagawa, K., Okazawa, H., Arikawa-Hirasawa, E., Nitta, N., Aoki, I., Aoki, S., 2017. Understanding microstructure of the brain by comparison of neurite orientation dispersion and density imaging (NODDI) with transparent mouse brain. Acta Radiol Open 6, 2058460117703816. https://doi.org/10.1177/2058460117703816

Saulle, M., Greenwald, B.D., 2012. Chronic traumatic encephalopathy: a review. Rehabil. Res. Pract. 2012, 816069. https://doi.org/10.1155/2012/816069

Schilling, K.G., Janve, V., Gao, Y., Stepniewska, I., Landman, B.A., Anderson, A.W., 2018. Histological validation of diffusion MRI fiber orientation distributions and dispersion. Neuroimage 165, 200-221. https://doi.org/10.1016/j.neuroimage.2017.10.046

Schlaffke, L., Lissek, S., Lenz, M., Brüne, M., Juckel, G., Hinrichs, T., Platen, P., Tegenthoff, M., Schmidt-Wilcke, T., 2014. Sports and brain morphology - a voxel-based morphometry study with endurance athletes and martial artists. Neuroscience 259, 35-42. https://doi.org/10.1016/j.neuroscience.2013.11.046

Schmahmann, J.D., Pandya, D.N., 2006. Fiber Pathways of the Brain. Oxford University Press, New York. https://doi.org/10.1093/acprof:oso/9780195104233.001.0001

Schneider, D.K., Galloway, R., Bazarian, J., Diekfuss, J.A., Dudley, J., Leach, J., Mannix, R., Talavage, T.M., Yuan, W., Myer, G.D., 2019. Diffusion Tensor Imaging in Athletes Sustaining Repetitive Head Impacts: A Systematic Review of Prospective Studies. J. Neurotrauma. https://doi.org/10.1089/neu.2019.6398

Schneider, T., Brownlee, W., Zhang, H., Ciccarelli, O., Miller, D.H., Wheeler-Kingshott, C.G., 2017. Sensitivity of multi-shell NODDI to multiple sclerosis white matter changes: a pilot study. Funct. Neurol. 32, 97-101. https://doi.org/10.11138/fneur/2017.32.2.097

Schranz, A.L., Manning, K.Y., Dekaban, G.A., Fischer, L., Jevremovic, T., Blackney, K., Barreira, C., Doherty, T.J., Fraser, D.D., Brown, A., Holmes, J., Menon, R.S., Bartha, R., 2018. Reduced brain glutamine in female varsity rugby athletes after concussion and in non-concussed athletes after a season of play. Hum. Brain Mapp. 39, 1489-1499. https://doi.org/10.1002/hbm.23919

Scott, S.K., Blank, C.C., Rosen, S., Wise, R.J., 2000. Identification of a pathway for intelligible speech in the left temporal lobe. Brain $123 \mathrm{Pt}$ 12, 2400-2406. https://doi.org/10.1093/brain/123.12.2400

Segonne, F., Dale, A.M., Busa, E., Glessner, M., Salat, D., Hahn, H.K., Fischl, B., 2004. A hybrid approach to the skull stripping problem in MRI. Neuroimage 22, 1060-1075. https://doi.org/10.1016/j.neuroimage.2004.03.032

Segonne, F., Pacheco, J., Fischl, B., 2007. Geometrically accurate topology-correction of cortical surfaces using nonseparating loops. IEEE Trans. Med. Imaging 26, 518-529.

Seo, D.-Y., Heo, J.-W., Ko, J.R., Kwak, H.-B., 2019. Exercise and Neuroinflammation in Health and Disease. Int. Neurourol. J. 23, S82-92. https://doi.org/10.5213/inj.1938214.107

Sepehrband, F., Clark, K.A., Ullmann, J.F.P., Kurniawan, N.D., Leanage, G., Reutens, D.C., Yang, Z., 2015. Brain 
tissue compartment density estimated using diffusion-weighted MRI yields tissue parameters consistent with histology. Hum. Brain Mapp. 36, 3687-3702. https://doi.org/10.1002/hbm.22872

Shultz, S.R., MacFabe, D.F., Foley, K.A., Taylor, R., Cain, D.P., 2012. Sub-concussive brain injury in the Long-Evans rat induces acute neuroinflammation in the absence of behavioral impairments. Behav. Brain Res. 229, 145-152. https://doi.org/10.1016/j.bbr.2011.12.015

Singh-Curry, V., Husain, M., 2009. The functional role of the inferior parietal lobe in the dorsal and ventral stream dichotomy. Neuropsychologia 47, 1434-1448. https://doi.org/10.1016/j.neuropsychologia.2008.11.033

Skinner, N.P., Kurpad, S.N., Schmit, B.D., Budde, M.D., 2015. Detection of acute nervous system injury with advanced diffusion-weighted MRI: a simulation and sensitivity analysis. NMR Biomed. 28, 1489-1506. https://doi.org/10.1002/nbm.3405

Slobounov, S.M., Walter, A., Breiter, H.C., Zhu, D.C., Bai, X., Bream, T., Seidenberg, P., Mao, X., Johnson, B., Talavage, T.M., 2017. The effect of repetitive subconcussive collisions on brain integrity in collegiate football players over a single football season: A multi-modal neuroimaging study. Neurolmage: Clinical 14, 708-718. https://doi.org/10.1016/j.nicl.2017.03.006

Smith, D.H., 2016. Neuromechanics and Pathophysiology of Diffuse Axonal Injury in Concussion. Bridg. Wash. D C 46, 79-84.

Smith, R.E., Tournier, J.-D., Calamante, F., Connelly, A., 2012. Anatomically-constrained tractography: improved diffusion MRI streamlines tractography through effective use of anatomical information. Neuroimage 62, 1924-1938. https://doi.org/10.1016/j.neuroimage.2012.06.005

Smith, S.M., 2002. Fast robust automated brain extraction. Hum. Brain Mapp. 17, 143-155. https://doi.org/10.1002/hbm.10062

Smith, S.M., Jenkinson, M., Woolrich, M.W., Beckmann, C.F., Behrens, T.E.J., Johansen-Berg, H., Bannister, P.R., De Luca, M., Drobnjak, I., Flitney, D.E., Niazy, R.K., Saunders, J., Vickers, J., Zhang, Y., De Stefano, N., Brady, J.M., Matthews, P.M., 2004. Advances in functional and structural MR image analysis and implementation as FSL. Neuroimage 23 Suppl 1, S208-19. https://doi.org/10.1016/j.neuroimage.2004.07.051

Sollmann, N., Echlin, P.S., Schultz, V., Viher, P.V., Lyall, A.E., Tripodis, Y., Kaufmann, D., Hartl, E., Kinzel, P., Forwell, L.A., Johnson, A.M., Skopelja, E.N., Lepage, C., Bouix, S., Pasternak, O., Lin, A.P., Shenton, M.E., Koerte, I.K., 2018. Sex differences in white matter alterations following repetitive subconcussive head impacts in collegiate ice hockey players. Neuroimage Clin 17, 642-649. https://doi.org/10.1016/j.nicl.2017.11.020

Stamm, J.M., Koerte, I.K., Muehlmann, M., Pasternak, O., Bourlas, A.P., Baugh, C.M., Giwerc, M.Y., Zhu, A., Coleman, M.J., Bouix, S., Fritts, N.G., Martin, B.M., Chaisson, C., McClean, M.D., Lin, A.P., Cantu, R.C., Tripodis, Y., Stern, R.A., Shenton, M.E., 2015. Age at First Exposure to Football Is Associated with Altered Corpus Callosum White Matter Microstructure in Former Professional Football Players. J. Neurotrauma 32, 1768-1776. https://doi.org/10.1089/neu.2014.3822

Stewart, C.A., Cockerill, T., Foster, I., Hancock, D.Y., Merchant, N., Skidmore, E., Stanzione, D., Taylor, J., Tuecke, S., Turner, G., Vaughn, M., Gaffney, N.I., 2015. Jetstream: A self-provisioned, scalable science and engineering cloud environment. https://doi.org/10.1145/2792745.2792774

Strauss, S.B., Fleysher, R., Ifrah, C., Hunter, L., Ye, K., Lipton, R., Zimmerman, M., Kim, M., Stewart, W., Lipton, M.L., 2020. Framing potential for adverse effects of repetitive subconcussive impacts in soccer in the context of athlete and non-athlete controls. Brain Imaging Behav. https://doi.org/10.1007/s11682-020-00297-4

Suzuki, H., Gao, H., Bai, W., Evangelou, E., Glocker, B., O’Regan, D.P., Elliott, P., Matthews, P.M., 2017. Abnormal brain white matter microstructure is associated with both pre-hypertension and hypertension. PLoS One 12, e0187600. https://doi.org/10.1371/journal.pone.0187600

Takemura, H., Caiafa, C.F., Wandell, B.A., Pestilli, F., 2016. Ensemble Tractography. PLoS Comput. Biol. 12, e1004692. https://doi.org/10.1371/journal.pcbi.1004692

Thomason, M.E., Thompson, P.M., 2011. Diffusion imaging, white matter, and psychopathology. Annu. Rev. Clin. Psychol. 7, 63-85. https://doi.org/10.1146/annurev-clinpsy-032210-104507

Tootell, R.B., Hadjikhani, N.K., Vanduffel, W., Liu, A.K., Mendola, J.D., Sereno, M.I., Dale, A.M., 1998. Functional analysis of primary visual cortex (V1) in humans. Proc. Natl. Acad. Sci. U. S. A. 95, 811-817. https://doi.org/10.1073/pnas.95.3.811

Tournier, J.D., Calamante, F., Connelly, A., 2010. Improved probabilistic streamlines tractography by 2nd order integration over fibre orientation distributions, in: Proceedings of the International Society for Magnetic Resonance in Medicine. Ismrm.

Tournier, J.-D., Calamante, F., Gadian, D.G., Connelly, A., 2004. Direct estimation of the fiber orientation density function from diffusion-weighted MRI data using spherical deconvolution. Neuroimage 23, 1176-1185. https://doi.org/10.1016/j.neuroimage.2004.07.037

Tournier, J.-D., Smith, R., Raffelt, D., Tabbara, R., Dhollander, T., Pietsch, M., Christiaens, D., Jeurissen, B., Yeh, 
C.-H., Connelly, A., 2019. MRtrix3: A fast, flexible and open software framework for medical image processing and visualisation. Neuroimage 202, 116137. https://doi.org/10.1016/j.neuroimage.2019.116137

Towns, J., Cockerill, T., Dahan, M., Foster, I., Gaither, K., Grimshaw, A., Hazlewood, V., Lathrop, S., Lifka, D., Peterson, G.D., Roskies, R., Scott, J.R., Wilkins-Diehr, N., 2014. XSEDE: Accelerating Scientific Discovery. Computing in Science Engineering 16, 62-74. https://doi.org/10.1109/MCSE.2014.80

Tremblay, S., Pascual-Leone, A., Théoret, H., 2018. A review of the effects of physical activity and sports concussion on brain function and anatomy. Int. J. Psychophysiol. 132, 167-175. https://doi.org/10.1016/j.ijpsycho.2017.09.005

Tustison, N.J., Cook, P.A., Klein, A., Song, G., Das, S.R., Duda, J.T., Kandel, B.M., van Strien, N., Stone, J.R., Gee, J.C., Avants, B.B., 2014. Large-scale evaluation of ANTs and FreeSurfer cortical thickness measurements. Neuroimage 99, 166-179. https://doi.org/10.1016/j.neuroimage.2014.05.044

Veraart, J., Novikov, D.S., Christiaens, D., Ades-Aron, B., Sijbers, J., Fieremans, E., 2016. Denoising of diffusion MRI using random matrix theory. Neuroimage 142, 394-406. https://doi.org/10.1016/j.neuroimage.2016.08.016

Voss, M.W., Heo, S., Prakash, R.S., Erickson, K.I., Alves, H., Chaddock, L., Szabo, A.N., Mailey, E.L., Wójcicki, T.R., White, S.M., Gothe, N., McAuley, E., Sutton, B.P., Kramer, A.F., 2013. The influence of aerobic fitness on cerebral white matter integrity and cognitive function in older adults: results of a one-year exercise intervention. Hum. Brain Mapp. 34, 2972-2985. https://doi.org/10.1002/hbm.22119

Voss, M.W., Nagamatsu, L.S., Liu-Ambrose, T., Kramer, A.F., 2011. Exercise, brain, and cognition across the life span. J. Appl. Physiol. 111, 1505-1513. https://doi.org/10.1152/japplphysiol.00210.2011

Wandell, B.A., 2016. Clarifying Human White Matter. Annu. Rev. Neurosci. 39, 103-128. https://doi.org/10.1146/annurev-neuro-070815-013815

Wang, N., Zhang, J., Cofer, G., Qi, Y., Anderson, R.J., White, L.E., Allan Johnson, G., 2019. Neurite orientation dispersion and density imaging of mouse brain microstructure. Brain Struct. Funct. 224, 1797-1813. https://doi.org/10.1007/s00429-019-01877-x

Wang, Z., Zhang, S., Liu, C., Yao, Y., Shi, J., Zhang, J., Qin, Y., Zhu, W., 2019. A study of neurite orientation dispersion and density imaging in ischemic stroke. Magn. Reson. Imaging 57, 28-33. https://doi.org/10.1016/j.mri.2018.10.018

Waskom, M., Others, 2020. mwaskom/seaborn: v0. 10.1 (April 2020). Zenodo, doi 10.

Wassermann, D., Makris, N., Rathi, Y., Shenton, M., Kikinis, R., Kubicki, M., Westin, C.-F., 2016. The white matter query language: a novel approach for describing human white matter anatomy. Brain Struct. Funct. 221, 4705-4721. https://doi.org/10.1007/s00429-015-1179-4

Woolrich, M.W., Jbabdi, S., Patenaude, B., Chappell, M., Makni, S., Behrens, T., Beckmann, C., Jenkinson, M., Smith, S.M., 2009. Bayesian analysis of neuroimaging data in FSL. Neuroimage 45, S173-86. https://doi.org/10.1016/j.neuroimage.2008.10.055

Yeatman, J.D., Dougherty, R.F., Myall, N.J., Wandell, B.A., Feldman, H.M., 2012. Tract profiles of white matter properties: automating fiber-tract quantification. PLoS One 7, e49790. https://doi.org/10.1371/journal.pone.0049790

Yi, S.Y., Barnett, B.R., Torres-Velázquez, M., Zhang, Y., Hurley, S.A., Rowley, P.A., Hernando, D., Yu, J.-P.J., 2019. Detecting Microglial Density With Quantitative Multi-Compartment Diffusion MRI. Front. Neurosci. 13, 81. https://doi.org/10.3389/fnins.2019.00081

Yoshimine, S., Ogawa, S., Horiguchi, H., Terao, M., Miyazaki, A., Matsumoto, K., Tsuneoka, H., Nakano, T., Masuda, Y., Pestilli, F., 2018. Age-related macular degeneration affects the optic radiation white matter projecting to locations of retinal damage. Brain Struct. Funct. 223, 3889-3900. https://doi.org/10.1007/s00429-018-1702-5

Yuan, W., Barber Foss, K.D., Thomas, S., DiCesare, C.A., Dudley, J.A., Kitchen, K., Gadd, B., Leach, J.L., Smith, D., Altaye, M., Gubanich, P., Galloway, R.T., McCrory, P., Bailes, J.E., Mannix, R., Meehan, W.P., 3rd, Myer, G.D., 2018. White matter alterations over the course of two consecutive high-school football seasons and the effect of a jugular compression collar: A preliminary longitudinal diffusion tensor imaging study. Hum. Brain Mapp. 39, 491-508. https://doi.org/10.1002/hbm.23859

Zhang, H., Hubbard, P.L., Parker, G.J.M., Alexander, D.C., 2011. Axon diameter mapping in the presence of orientation dispersion with diffusion MRI. Neuroimage 56, 1301-1315. https://doi.org/10.1016/j.neuroimage.2011.01.084

Zhang, H., Schneider, T., Wheeler-Kingshott, C.A., Alexander, D.C., 2012. NODDI: practical in vivo neurite orientation dispersion and density imaging of the human brain. Neuroimage 61, 1000-1016. https://doi.org/10.1016/j.neuroimage.2012.03.072

Zhang, J., Yoganandan, N., Pintar, F.A., Gennarelli, T.A., 2006. Brain strains in vehicle impact tests. Annu. Proc. 
Assoc. Adv. Automot. Med. 50, 1-12.

Zhang, L., Rzigalinski, B.A., Ellis, E.F., Satin, L.S., 1996. Reduction of voltage-dependent Mg2+ blockade of NMDA current in mechanically injured neurons. Science 274, 1921-1923. 